RAFAEL VIANA BENZE

MODELAGEM MATEMÁTICA DO PROCESSO TÉRMICO CONTÍNUO DE ALIMENTOS LÍQUIDOS EM TROCADORES DE CALOR A PLACAS

São Paulo

2013 


\section{MODELAGEM MATEMÁTICA DO PROCESSO TÉRMICO CONTÍNUO DE ALIMENTOS LÍQUIDOS EM TROCADORES DE CALOR A PLACAS}

Dissertação apresentada à Escola Politécnica da Universidade de São Paulo para obtenção do Título de Mestre em

Engenharia 


\section{MODELAGEM MATEMÁTICA DO PROCESSO TÉRMICO CONTÍNUO DE ALIMENTOS LÍQUIDOS EM TROCADORES DE CALOR A PLACAS}

Dissertação apresentada à Escola Politécnica da Universidade de São Paulo para obtenção do Título de Mestre em Engenharia

Área de Concentração:

Engenharia Química

Orientador: Prof. Dr. Jorge Andrey Wilhelms Gut 
Este exemplar foi revisado e corrigido em relação à versão original, sob responsabilidade única do autor e com a anuência de seu orientador.

São Paulo, de maio de 2013.

Assinatura do autor

Assinatura do orientador

FICHA CATALOGRÁFICA

Benze, Rafael Viana

Modelagem matemática do processo térmico contínuo de alimentos líquidos em trocadores de calor a placas / R.V. Benze. - versão corr.-- São Paulo, 2013.

$74 \mathrm{p}$.

Dissertação (Mestrado) - Escola Politécnica da Universidade de São Paulo. Departamento de Engenharia Química.

1. Alimentos líquidos (Modelagem matemática) 2. Trocadores de calor I. Universidade de São Paulo. Escola Politécnica. Departamento de Engenharia Química II. t. 
Aos meus pais, Zenaide e Luiz, à minha irmã, Carolina e à minha querida Helena, com grande carinho e admiração. 
"Mit dem Wissen wächst der

Zweifel"

(Johann Wolfgang von

Goethe) 


\section{AGRADECIMENTOS}

Ao meu orientador Prof. Jorge Gut, pela paciência, acompanhamento e oportunidade.

Ao Prof. Antonio Carlos, ao Prof. Pedro Alcântara e ao Prof. Marcelo Seckler pelas sugestões e contribuições na elaboração desse trabalho.

Aos colegas de laboratório Ewerton Ferrão, Jorge Trocolli, Paula Pegoraro, Lina Maria, Ana Maria, Arlet Patrícia, Carola Gutierrez, Otília Teixeira e Luz Altuna pelos conselhos, risadas e confraternizações. Aos funcionários Ivan Nunes e Vanessa Duarte, pelo apoio.

Aos amigos Vinícios, Danielle e Aline pelos momentos de diversão e ajuda nas situações mais delicadas.

À querida Helena pelas palavras e atos de carinho que acompanharam o desenvolvimento desse trabalho e tornaram esse período inesquecível. Pela ajuda e conhecimento que fizeram ser possível a elaboração dessa pesquisa e pela companhia especial em todos os momentos.

Aos meus admiráveis pais, Luiz e Zenaide, que sempre me incentivaram, me apoiaram e me motivaram diariamente, participando e sendo fundamentais em todas minhas conquistas e momentos felizes.

À minha irmã, médica e educadora, Carolina, pelo exemplo de conduta, dedicação e sabedoria.

À CAPES pela bolsa cedida.

A todos que me presentearam com atenção e conselhos, ajudando-me a enfrentar e superar dificuldades e questionamentos. 


\section{RESUMO}

O principal objetivo do trabalho foi o desenvolvimento de um modelo matemático de um pasteurizador a placas visando a determinação da distribuição de temperatura e de letalidade ao longo dos canais do trocador de calor em todas as suas seções, nas conexões tubulares e no tubo de retenção para a avaliação do decaimento logarítmico da concentração de um microorganismo alvo ou da atividade de uma enzima alvo em um processo de pasteurização contínua. A modelagem matemática foi composta pelo balanço diferencial de energia e letalidade nos canais do trocador, no tubo de retenção e nas suas conexões, levando em conta a perda de calor para o ambiente nos tubos. O modelo construído apresentou um conjunto de equações diferenciais ordinárias de primeira ordem e sua resolução foi feita pelo método das diferenças finitas usando o software gPROMS. Um estudo de caso foi analisado e a modelagem descreveu de forma coerente o processo térmico e a letalidade e futuramente ela poderá ser utilizada para a otimização do processo de pasteurização em trocadores de calor a placas, visando a obtenção de produtos seguros e de alta qualidade. A verificação do processo de pasteurização que o modelo desenvolvido contempla foi realizada a partir da validação experimental utilizando um integrador tempo-temperatura e ensaios laboratoriais com indicador enzimático (fosfatase alcalina em tampão fosfato), que mostraram que o modelo desenvolvido se aproxima de maneira satisfatória dos resultados reais.

Palavras-chave: Modelagem matemática. Pasteurização. Processamento térmico. Trocador de calor a placas. Simulação. 


\begin{abstract}
The main objective of this study was to develop a mathematical model in a plate pasteurizer in order to determine the temperature and lethality distribution along the channels of the heat exchanger in all its sections, in tubular connections and holding tube evaluating the logarithmic decay in concentration of a target microorganism or enzyme activity in a continuous pasteurization process. Mathematical modeling was composed of the differential energy balance and lethality in the channels of the exchanger, the holding tube and its connections, taking into account the heat loss to the environment in the tubes. The constructed model presented a set of ordinary differential equations of first order and its resolution was made by the finite difference method using the gPROMS software. A case study was analyzed and the modeling described the thermal and the lethality process very well and in the future it can be used to optimize the process of pasteurization in plate heat exchangers, aiming the achievement of safe and with high quality products. A verification of the pasteurization process that the model developed contemplates has been performed based on experimental validation using time-temperature integrator and testing with enzymatic indicator (alkaline phosphatase in phosphate buffer), which showed that the model developed satisfactorily approximates the actual results.
\end{abstract}

Keywords: Mathematical modeling. Pasteurization. Thermal processing. Plate heat exchanger. Simulation. 


\section{LISTA DE FIGURAS}

Figura 2-1: Unidade de pasteurização e seções de um trocador de calor a

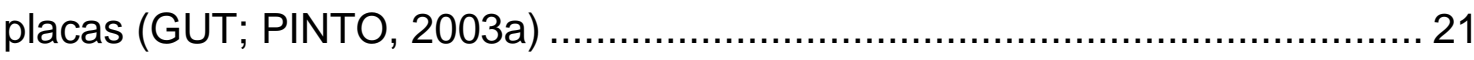

Figura 2-2: Principais componentes de um trocador de calor a placas (GUT,

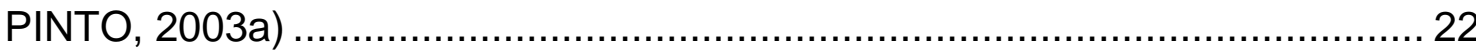

Figura 2-3: Exemplo de escoamento dos fluidos dentro de um PHE (ALFA

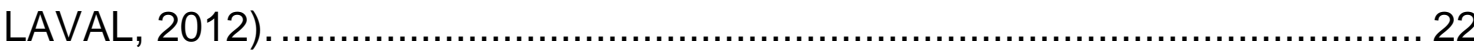

Figura 2-4: Esquema com os parâmetros para descrição da configuração de um trocador de calor a placas (GUT, 2003) 23

Figura 3-1: Esquema do volume de controle usado para o balanço diferencial de energia no canal do trocador de calor (GUT, 2003). 32

Figura 3-2: Exemplo de um arranjo em série de um PHE com 12 canais (GUTIERREZ, 2012).

Figura 3-3: Volume de controle para o balanço de energia nos tubos (GUTIERREZ, 2012). 38

Figura 4-1: Foto do pasteurizador laboratorial FT-43 (Armfield, UK). 44

Figura 4-2: Dimensões da gaxeta do trocador de calor a placas $(\mathrm{mm})$ (GUTIERREZ, 2012).

Figura 4-3: Esquema do pasteurizador com pontos de interesse destacados (AGUIAR, 2009).

Figura 5-1: Distribuição de temperatura e valor de esterilização simulados para Coxiella burnetii usando tempo espacial. 55

Figura 5-2: Distribuição de temperatura e valor de esterilização simulados para Coxiella burnetii usando tempo médio de residência. 56

Figura 5-3: Distribuição de temperatura experimental e simulada para processamento do indicador enzimático a $70{ }^{\circ} \mathrm{C}$.

Figura 5-4: Distribuição de temperatura experimental e simulada para processamento do indicador enzimático a $75^{\circ} \mathrm{C}$.

Figura 5-5: Distribuição de temperatura experimental e simulada para processamento do indicador enzimático a $80^{\circ} \mathrm{C}$.

Figura 5-6: Distribuição de temperatura experimental e simulada para processamento do indicador enzimático a $85^{\circ} \mathrm{C}$. 63 
Figura 5-7: Histórico da atividade residual do indicador enzimático ao longo do pasteurizador para processamento a $70^{\circ} \mathrm{C}$ 64

Figura 5-8: Histórico da atividade residual do indicador enzimático ao longo do pasteurizador para processamento a $75^{\circ} \mathrm{C}$ 64

Figura 5-9: Histórico da atividade residual do indicador enzimático ao longo do pasteurizador para processamento a $80^{\circ} \mathrm{C}$ 65 Figura 5-10: Histórico da atividade residual do indicador enzimático ao longo do pasteurizador para processamento a $85^{\circ} \mathrm{C}$ 65 Figura 5-11: Atividade residual experimental e simulada da enzima na saída do aquecimento para processamento a $70,75,80$ e $85^{\circ} \mathrm{C}$ 67 Figura 5-12: Atividade residual experimental e simulada da enzima na saída do resfriamento para processamento a $70,75,80$ e $85^{\circ} \mathrm{C}$. 68 


\section{LISTA DE TABELAS}

Tabela 4-1: Características das placas do trocador de calor (GUTIERREZ,

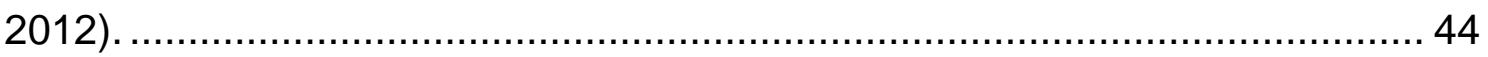

Tabela 4-2: Características do tubo de retenção e conexões. .......................... 46

Tabela 4-3: Descrição da localização dos pontos de interesse do processo de

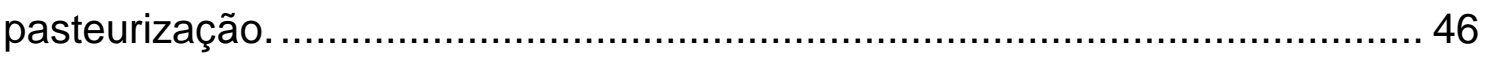

Tabela 4-4: Principais parâmetros das seções do trocador de calor................ 47

Tabela 4-5: Parâmetros numéricos da equação de Nusselt (AGUIAR, 2009).. 47

Tabela 4-6: Tempo espacial e tempo médio de residência em cada seção do

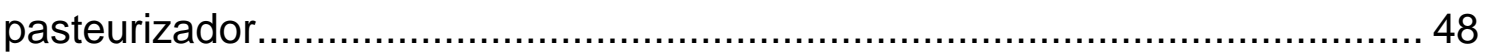

Tabela 4-7: Número de Reynolds em cada seção do pasteurizador................ 49

Tabela 4-8: Parâmetros cinéticos referentes à inativação da Coxiella burnetii

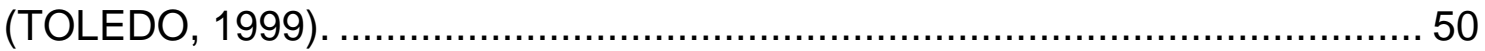

Tabela 4-9: Temperatura dos fluidos de atividade adotados na simulação...... 50 Tabela 4-10: Coeficientes globais de troca térmica entre fluido e ar ambiente das conexões e tubo de retenção (GUTIERREZ, 2012). ................................ 50

Tabela 4-11: Parâmetros cinéticos do indicador enzimático nas temperaturas processadas (AGUIAR; YAMASHITA; GUT, 2012) ................................... 52

Tabela 5-1: Valor de esterilização para Coxiella burnetii do estudo de caso na saída de cada seção do pasteurizador ...................................................... 57

Tabela 5-2: Dados experimentais de atividade enzimática coletados (U/L) ..... 59

Tabela 5-3: Dados experimentais de temperatura coletados........................... 60

Tabela 5-4: Balanço de energia com valores experimentais nas três seções do

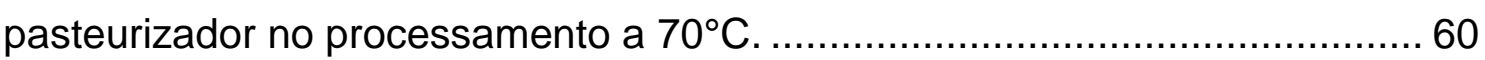

Tabela 5-5: Balanço de energia com valores experimentais nas três seções do

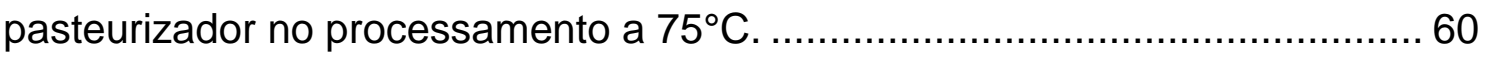

Tabela 5-6: Balanço de energia com valores experimentais nas três seções do

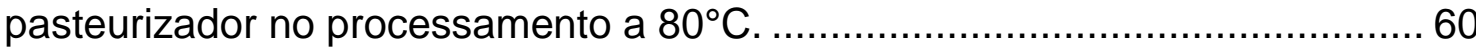

Tabela 5-7: Balanço de energia com valores experimentais nas três seções do pasteurizador no processamento a $85^{\circ} \mathrm{C}$

Tabela 5-8: Atividade residual do indicador enzimático em cada trecho do pasteurizador nas simulações de tempo médio de residência e tempo espacial. 


\section{LISTA DE ABREVIATURAS E SIGLAS}

ABIR Associação Brasileira das Indústrias de Refrigerantes e Bebidas Não Alcoólicas

ALP Alkaline Phosphatase, Fosfatase Alcalina

CFD Computational Fluid Dynamics, Fluidodinâmica Computacional

CFDM Centered Finite Difference Method, Método Centrado das

Diferenças Finitas

HTST High Temperature Short Time, Alta Temperatura Curto Tempo

LEA Laboratório de Engenharia de Alimentos

PHE Plate Heat Exchanger, Trocador de Calor a Placas

TTI Time-Temperature Integrator, Integrador Tempo-Temperatura

UHT Ultra High Temperature, Temperatura Ultra Alta 


\section{LISTA DE SÍMBOLOS}

$a_{i} \quad$ Parâmetro numérico da equação de Nusselt $i=1,2$ ou 3 (adimensional)

$a_{w} \quad$ Atividade de água (adimensional)

A Área de seção de escoamento $\left(\mathrm{m}^{2}\right)$

$A_{p} \quad$ Área de troca térmica de uma placa $\left(\mathrm{m}^{2}\right)$

$A R \quad$ Atividade enzimática residual (\%)

$A R_{0} \quad$ Atividade enzimática antes do tratamento térmico (\%)

$A R_{1} \quad$ Atividade da iso-enzima 1 termorresistente (\%)

$A R_{2} \quad$ Atividade da iso-enzima 2 termolábil (\%)

$A R_{f} \quad$ Atividade residual após tratamento térmico (\%)

$b \quad$ Espessura média do canal, distância média entre duas placas $(\mathrm{m})$

$C_{A} \quad$ Concentração da espécie A (UFC/m ou $\mathrm{kg} / \mathrm{m}^{3}$ ou U $/ \mathrm{m}^{3}$ )

$\mathrm{Cp}_{i} \quad$ Calor específico do fluido localizado no canal $i(\mathrm{~J} / \mathrm{kg} . \mathrm{K})$

d Diâmetro interno $(\mathrm{m})$

$D \quad$ Tempo de redução decimal (s)

$d_{e} \quad$ Diâmetro equivalente $(\mathrm{m})$

$d_{p} \quad$ Diâmetro do orifício $(\mathrm{m})$

$D_{\text {REF }} \quad$ Tempo de redução decimal a uma temperatura de referência (s)

$h \quad$ Coeficiente convectivo de troca térmica $\left(\mathrm{W} / \mathrm{m}^{2} . \mathrm{K}\right)$

i Contador genérico (adimensional)

$j \quad$ Contador genérico (adimensional)

$k \quad$ Condutividade térmica (W/m.K)

$k_{p} \quad$ Condutividade térmica da placa $(\mathrm{W} / \mathrm{m} . \mathrm{K})$

$L \quad$ Comprimento da placa medido entre as bases dos orifícios $(\mathrm{m})$

$L_{t} \quad$ Comprimento do tubo $(\mathrm{m})$

$N \quad$ Número de canais por passe (adimensional)

$N_{c} \quad$ Número de canais (adimensional)

$\mathrm{Nu} \quad$ Número de Nusselt (adimensional)

$P \quad$ Número de passes (adimensional)

$P^{\prime}, P^{\prime \prime} \quad$ Número de passes nos lados I ou II do trocador de calor a placas (adimensional) 


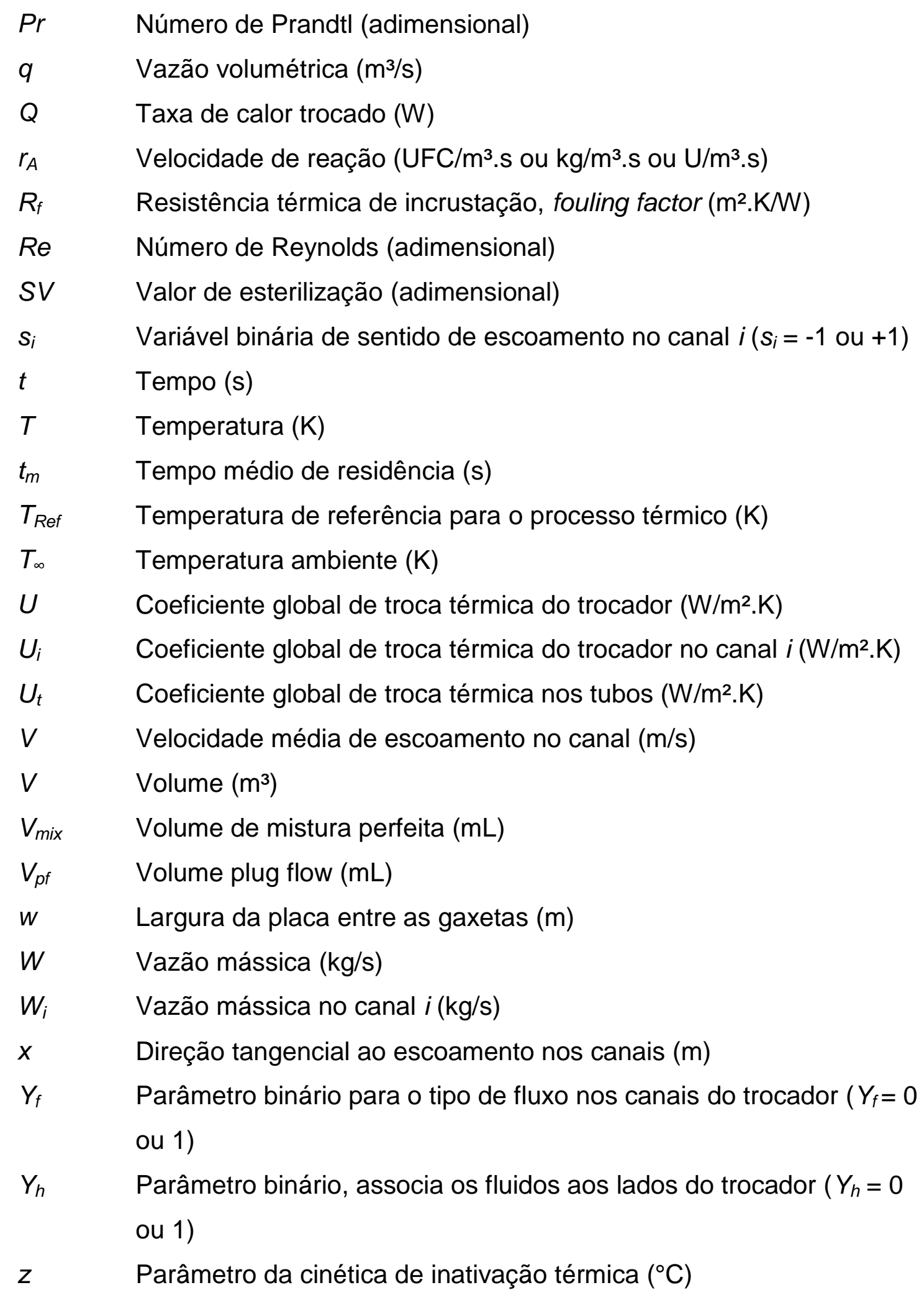




\section{LETRAS GREGAS}

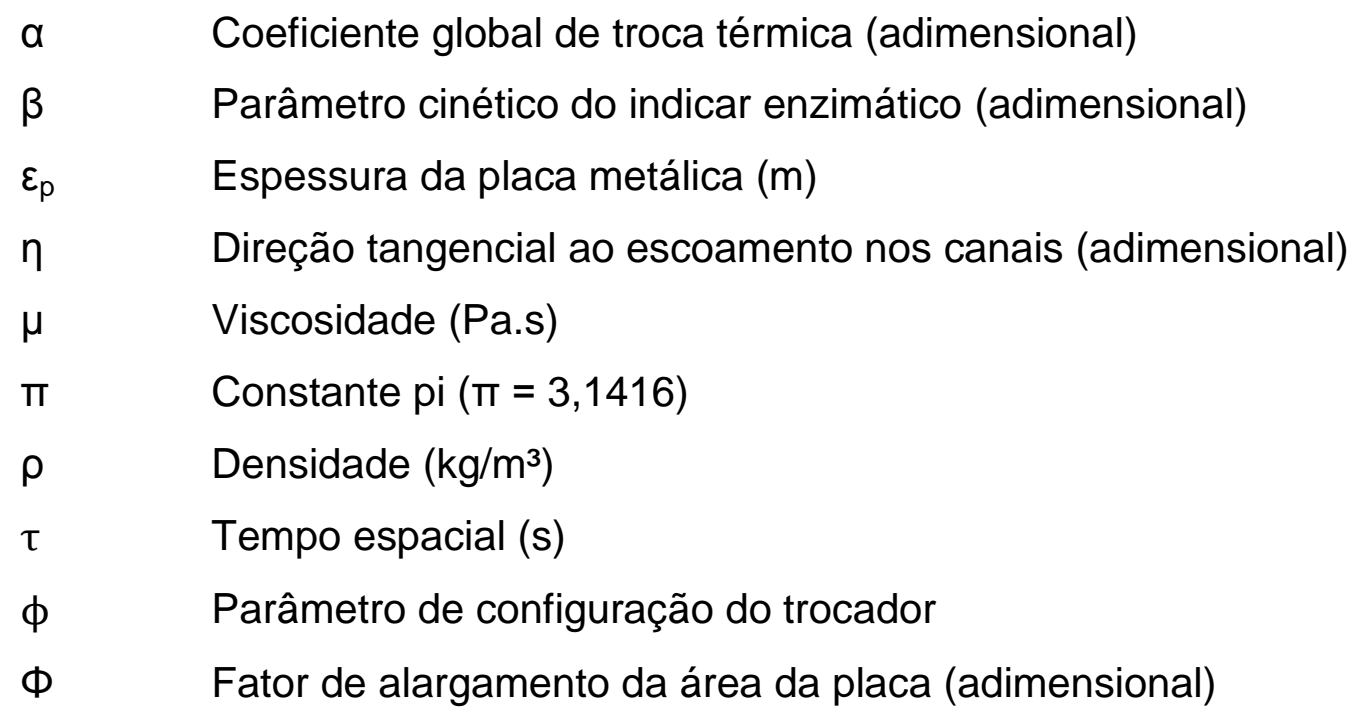

\section{SUBSCRITOS}

$\begin{array}{ll}\text { cold } & \text { Fluido frio ou de resfriamento } \\ \text { hot } & \text { Fluido quente ou de aquecimento } \\ i & \text { Elemento genérico } i \\ j & \text { Elemento genérico } j \\ \text { in } & \text { Entrada } \\ \text { out } & \text { Saída }\end{array}$

\section{SOBRESCRITOS}

I Lado I do trocador (conjunto de canais ímpares)

II Lado II do trocador (conjunto dos canais pares) 


\section{SUMÁRIO}

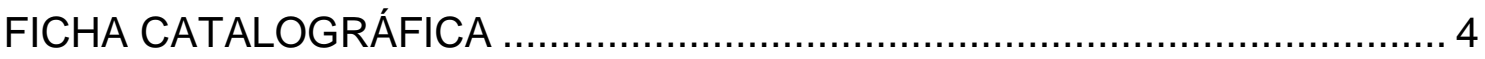

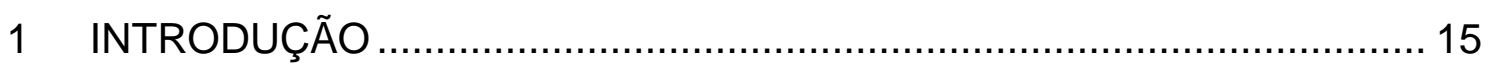

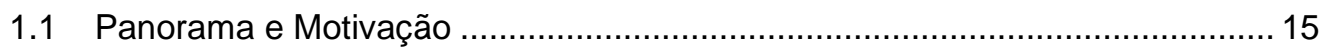

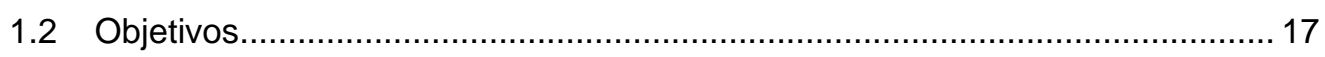

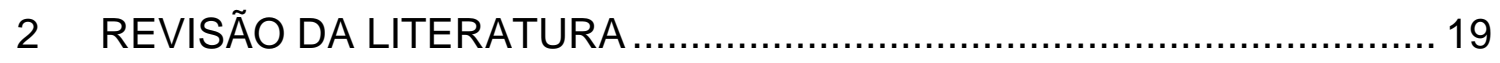

2.1 Processamento térmico de alimentos líquidos.............................................. 19

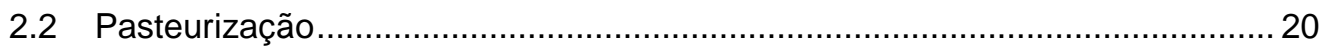

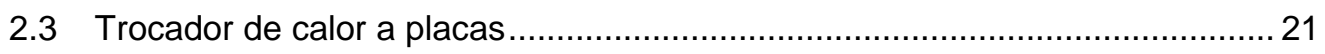

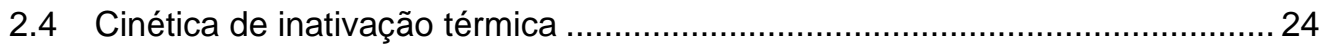

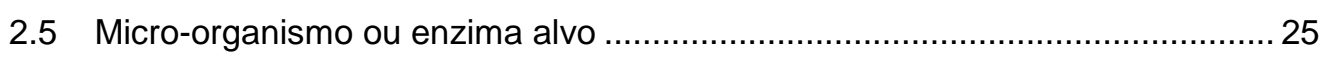

2.6 Modelagem e simulação do processo HTST em trocador a placas ..................26

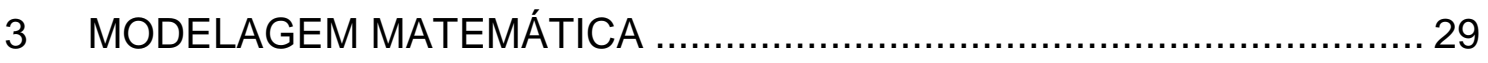

3.1 Distribuição de temperatura ................................................................. 30

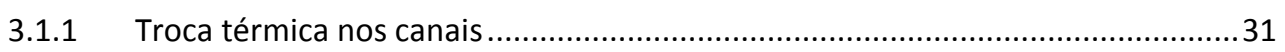

3.1.2 Troca térmica no tubo de retenção e conexões....................................................38

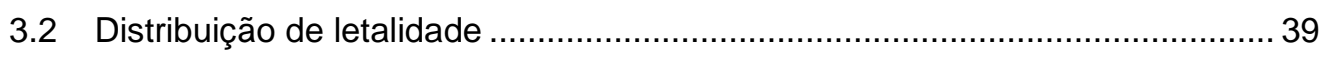

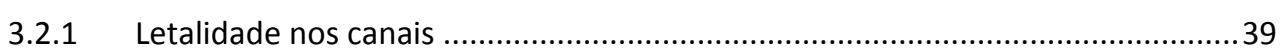

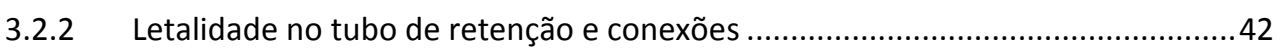

4 ESTUDO DE CASO E VALIDAÇÃO ………........................................ 43

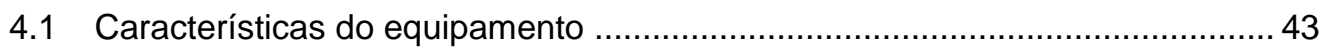

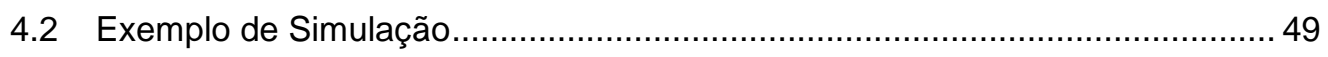

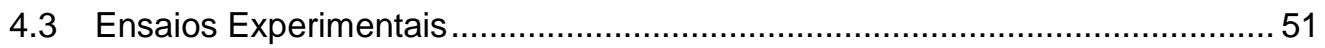

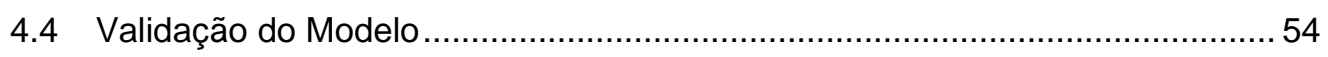

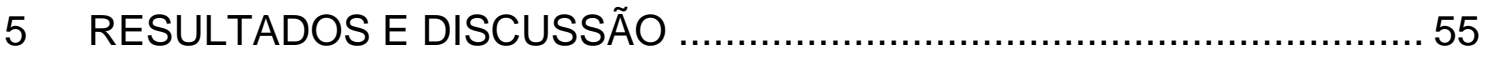

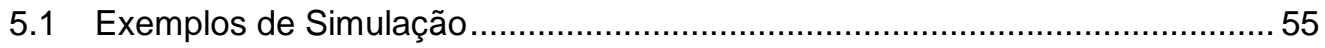

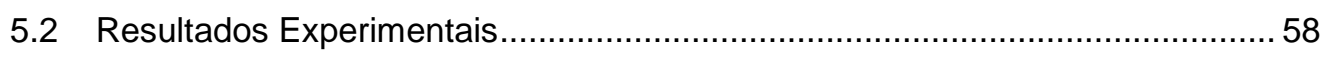

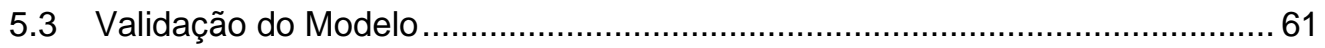

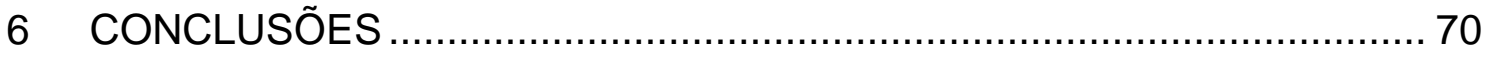

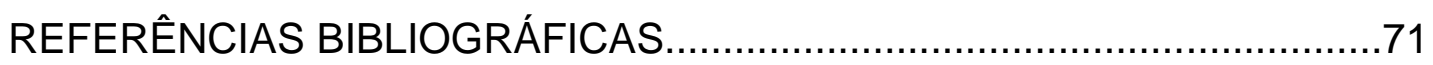




\section{INTRODUÇÃO}

\subsection{Panorama e Motivação}

É possível perceber que atualmente existe um maior conhecimento e busca dos consumidores por hábitos e alimentos cada vez mais saudáveis. A indústria de alimentos tem utilizado recursos para o preparo de processos que garantam a qualidade microbiológica enquanto minimizam a deterioração dos atributos de qualidade do alimento para assim satisfazer as expectativas dos consumidores cada vez mais exigentes. Durante a produção de alimentos seguros é feita uma escolha minuciosa das matérias primas, interrompe-se 0 crescimento microbiano (no caso da estocagem a baixas temperaturas) e reduz-se ou elimina-se a presença microbiana por processamento térmico com posterior prevenção de recontaminação. Para atingir as metas citadas e garantir a estabilidade e a segurança do alimento, é necessária a utilização de uma operação unitária que tenha como objetivo a inativação de microorganismos indesejáveis (LADO; YOUSSEF, 2002).

Esse tipo de operação unitária pode ser representada pela pasteurização, que é um processo térmico controlado, no qual um produto é aquecido até uma dada temperatura, mantido nesta temperatura por um determinado intervalo de tempo e então é rapidamente resfriado para em seguida ser armazenado (LEWIS; HEPPELL, 2000).

Um exemplo de alimento que pode passar por tratamento térmico antes de seu consumo é o suco de laranja. O consumo de suco de laranja natural pasteurizado, quando foi lançado no mercado brasileiro (1993), foi de 1 milhão de litros. Já em 1999 esse valor subiu para 160 milhões de litros e ultrapassou 200 milhões de litros em 2000. Esse consumo representa um faturamento anual de mais de $R \$ 500$ milhões (TRIBESS et al., 2003). Já em 2010 o consumo de suco de laranja foi de 311,3 milhões de litros (ABIR, 2012). Segundo a Associação Brasileira das Indústrias de Refrigerantes e Bebidas Não Alcoólicas (ABIR, 2012), a cada ano novas marcas, sabores, composições e embalagens de sucos prontos surgem nas prateleiras dos supermercados em 
todo o Brasil. Segundo estudos do Ministério da Agricultura, a projeção realizada até 2020 para a exportação de suco de laranja é de constante crescimento chegando a 3,5 milhões de toneladas anuais em 2020. Atualmente esse valor é de 2 milhões por ano (Ministério da Agricultura, Pecuária e Abastecimento, 2011). A constatação de que existe um constante crescimento do consumo de suco pasteurizado no Brasil mostra a importância de estudar o seu processo verificando como são afetados os principais micro-organismos presentes no produto cru.

Com o aumento do consumo e produção de sucos de fruta, é possível observar uma crescente competitividade entre as indústrias de processamento que acaba incentivando a otimização de processos e o desenvolvimento de novos equipamentos objetivando a redução de custos operacionais ou a maximização de receitas. É reservada atenção especial para a conservação de energia, devido à necessidade do seu uso racional e eficiente, e para os processos de recuperação de calor. Através de políticas de melhoria contínua, as indústrias vêm aperfeiçoando e inovando processos e princípios de operação (BEJAN et al., 1996).

Para atender às crescentes exigências da indústria, vêm sendo desenvolvidos trocadores de calor mais econômicos, compactos e eficientes, e nesse panorama o trocador de calor a placas, PHE (Plate Heat Exchanger), tem um grande destaque, já que devido a contínuos aperfeiçoamentos o seu uso na indústria alimentícia vem se intensificando desde a década de 1930 (PEARCE, 2001).

No processamento térmico contínuo a função do trocador é aquecer o alimento fluido até a temperatura de pasteurização especificada e resfriá-lo até a temperatura de estoque ou embalagem. Para fazer isso de forma eficiente, a entalpia do produto quente pode ser recuperada no pré-aquecimento do produto cru em uma seção de regeneração térmica. Os trocadores de calor a placas são muito utilizados para a pasteurização contínua HTST (High Temperature Short Time) de alimentos líquidos como leite, sucos ou cerveja. Em uma unidade HTST, o PHE é normalmente dividido em três seções (aquecimento, resfriamento e regeneração), interconectadas e ligadas ao tubo de retenção (LEWIS et al., 2000). 
Os trocadores de calor a placas são extensamente empregados em operações líquido-líquido com temperaturas e pressões moderadas e que exijam flexibilidade e alta eficiência térmica (HEWITT et al., 1994).

É importante observar que é necessária a criação de uma modelagem rigorosa do processo térmico que ocorre no pasteurizador a ser estudado para que seja viável a simulação e otimização do processo. Deve-se buscar, na otimização, a determinação de condições ótimas de operação, para que sejam minimizados os efeitos indesejados do aquecimento, garantindo a qualidade microbiológica do alimento e reduzindo custos operacionais do processo (GRIJSPEERDT et al., 2003).

Trabalhos anteriores realizados pelo grupo de pesquisa do Laboratório de Engenharia de Alimentos (LEA) desenvolveram e validaram a modelagem matemática para a distribuição de temperatura em trocadores de calor a placas que é adotada no presente trabalho. A principal contribuição da pesquisa existente nessa dissertação encontra-se na abordagem, desenvolvimento e acoplamento da modelagem matemática que caracteriza a distribuição de letalidade, em que a inativação do micro-organismo, enzima ou nutriente é apresentada pelo balanço material visto tipicamente em reatores tubulares, em que há o consumo de uma espécie reacional. Propõe-se esse tipo de abordagem, pois existem poucos trabalhos e estudos na literatura com essa visão, permitindo que resultados representativos do processo real possam ser obtidos de maneira eficaz.

\subsection{Objetivos}

Os objetivos principais do presente trabalho são:

- Acoplar um modelo matemático fenomenológico de distribuição de letalidade ao de temperatura e avaliar o impacto do processo sobre 0 produto em uma pasteurização contínua HTST em um trocador de calor a placas em operação estacionária. 
- Analisar a distribuição de temperatura e de letalidade ao longo de todas as etapas do processo.

- Realizar a validação experimental do modelo, confrontando resultados de simulação e experimentais, obtidos através de ensaios usando um integrador de tempo-temperatura. 


\section{REVISÃO DA LITERATURA}

\subsection{Processamento térmico de alimentos líquidos}

O processamento térmico continua sendo um dos métodos mais utilizados na conservação dos alimentos líquidos. O principal objetivo do processamento térmico é inativar complexos enzimáticos e micro-organismos patogênicos e deteriorantes, obtendo um alimento em condições seguras para o consumo e com boa vida de prateleira (RIBEIRO, 2009; LEWIS; HEPPELL, 2000).

De acordo com Fellows (2000), a destruição térmica de microorganismos é tradicionalmente estabelecida de modo a seguir uma taxa semilogarítmica de primeira ordem, mas para um intervalo de temperatura restrito pode-se considerar a cinética de primeira ordem. De um modo geral, o equacionamento de cinética de primeira ordem pode ser usada também para desnaturação de proteínas, destruição de esporos de bactérias e inativação enzimática (WALSTRA et al., 1999). A severidade de qualquer processo térmico deve ser conhecida e depende de fatores como: (i) características do produto alimentício, incluindo propriedades termo-físicas, formato e tamanho do recipiente contendo o produto, (ii) o tipo e resistência térmica do microorganismo alvo presente no alimento e (iii) $\mathrm{pH}$, atividade de água $\left(a_{w}\right)$ e composição do alimento.

Para estabelecer um processo térmico parte-se de duas premissas: a resistência térmica do micro-organismo alvo para uma dada formulação e composição de um produto e a taxa de aquecimento do produto. A determinação da taxa de aquecimento de um produto é realizada através de uma detalhada análise de parâmetros (tanto do produto quanto do sistema) que podem afetar o comportamento de aquecimento (AWUAH et al., 2007). 


\subsection{Pasteurização}

A pasteurização objetiva o tratamento térmico de produtos alimentícios líquidos para que sejam eliminados micro-organismos deterioradores, células vegetativas de micro-organismos patogênicos e enzimas indesejáveis, visando à garantia da segurança microbiológica (inocuidade) do alimento, preservando as características sensoriais e o valor nutricional. O sobre-processamento é indesejado, pois compromete as características do produto e eleva o consumo de utilidades de aquecimento e de resfriamento, afetando economicamente 0 processo. As condições do tratamento térmico são definidas tendo como base o micro-organismo ou enzima mais resistente presente no produto e o número de reduções decimais desejado para a sua população ou atividade. Em comparação com a esterilização, a pasteurização é um tratamento térmico brando, em que há um compromisso entre a segurança e a qualidade do produto final. A extensão do tempo de prateleira e a eliminação severa de esporos termoresistentes podem ser alcançadas pelo processo de esterilização contínua UHT (Ultra High Temperature). Na pasteurização, o produto final, diferentemente de uma esterilização total, não fica totalmente livre de microorganismos; porém o seu desenvolvimento fica dificultado pela maneira com que é feito o armazenamento do produto (LEWIS; HEPPELL, 2000).

Quando se deseja armazenar produtos alimentícios já tratados termicamente em condições que minimizam o crescimento bacteriano, como a refrigeração, recomenda-se a pasteurização como processo de tratamento térmico (FONSECA, 1984). Além disso, para sucos de frutas cítricas, a pasteurização é considerada um importante método de conservação, pois aumenta a sua estabilidade durante o transporte e a comercialização (ELEZMARTINEZ et al., 2007).

A Figura 2-1 mostra um trocador de calor com três seções (aquecimento, regeneração e resfriamento) e tubo de retenção, exemplificando um processo de pasteurização contínua HTST. 


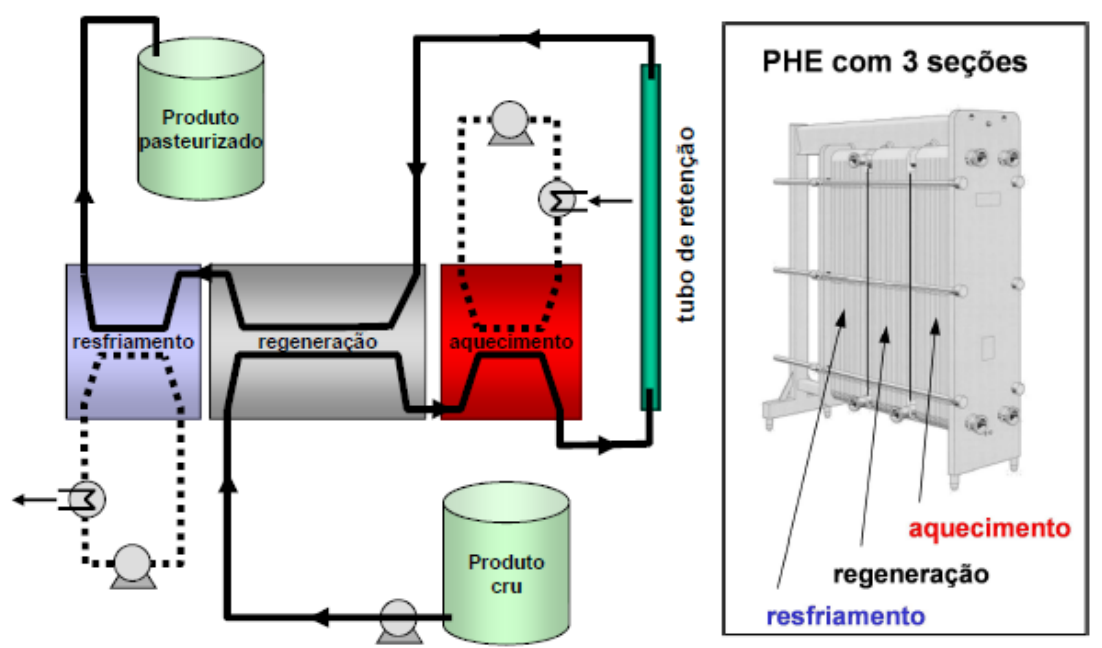

Figura 2-1: Unidade de pasteurização e seções de um trocador de calor a placas (GUT; PINTO, 2003a)

Em um processo de pasteurização, o controle da temperatura nas etapas do processo é imprescindível para o sucesso do mesmo, especialmente o controle da temperatura na saída do tubo de retenção, que é o encarregado de manter o produto no tempo e na temperatura definidos para o processo. Durante a passagem do produto pela retenção ocorre a destruição de microorganismos e a inativação de enzimas, portanto, se a temperatura de saída do tubo de retenção for menor do que a estabelecida, o produto terá que ser novamente processado para garantir a segurança microbiológica especificada. Caso a temperatura de saída seja maior, o produto estará sendo sobreprocessado, ocorrendo perda de qualidade sensorial e nutricional assim como aumento desnecessário nos custos de produção (IBARROLA et al., 2002).

\subsection{Trocador de calor a placas}

Trocadores de calor a placas são basicamente formados por um pacote de finas placas, com algum tipo de corrugação, prensadas em um pedestal. As placas têm orifícios para a passagem do fluido e gaxetas para formar canais de escoamento pelos quais os fluidos quente e frio circulam alternadamente, trocando calor através das placas metálicas (SHAH et al., 2003). O pedestal 
possui uma placa fixa, uma placa de aperto móvel, barramentos inferior e superior e parafusos de aperto. A placa fixa e a de aperto possuem bocais para conexão das tubulações de alimentação e de coleta dos fluidos (GUT; PINTO, 2003b). Um esquema da composição de um PHE é mostrado na Figura 2-2.
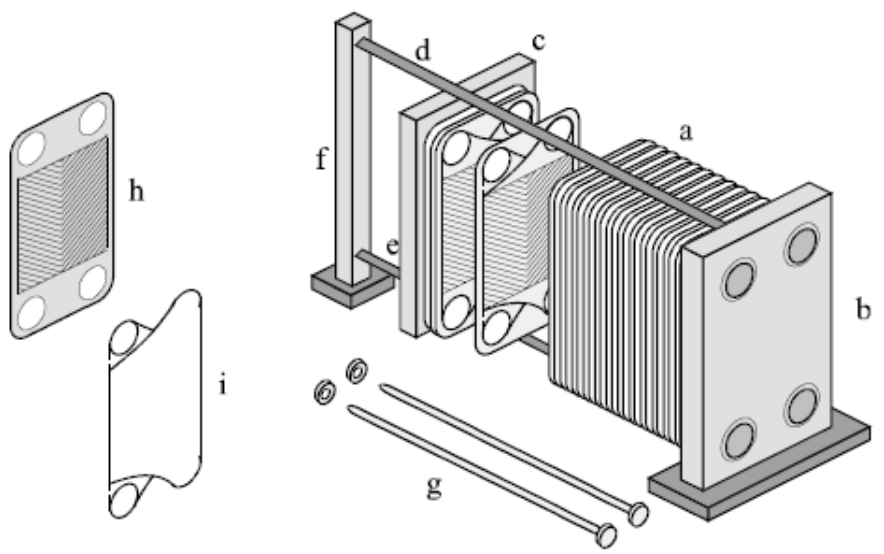

a. Pacote de placas aberto

b. Placa fixa com conexões

c. Placa de aperto móvel

d. Barramento superior

e. Barramento inferior

f. Coluna de sustentação

g. Parafusos de aperto

h. Placa corrugada chevron

i. Gaxeta

Figura 2-2: Principais componentes de um trocador de calor a placas (GUT, PINTO, 2003a)

O espaço que existe entre duas placas é chamado de canal de escoamento. A distribuição do fluxo pelos canais do trocador de calor é feita na forma de "passes", compostos por um determinado número de "passagens". $\mathrm{Na}$ mudança de sentido do fluxo ocorre a mudança de passe (GUT; PINTO, 2003b). A Figura 2-3 mostra um exemplo de configuração de um trocador, explicitando o caminho percorrido pelos fluidos quente e frio de uma dada configuração.

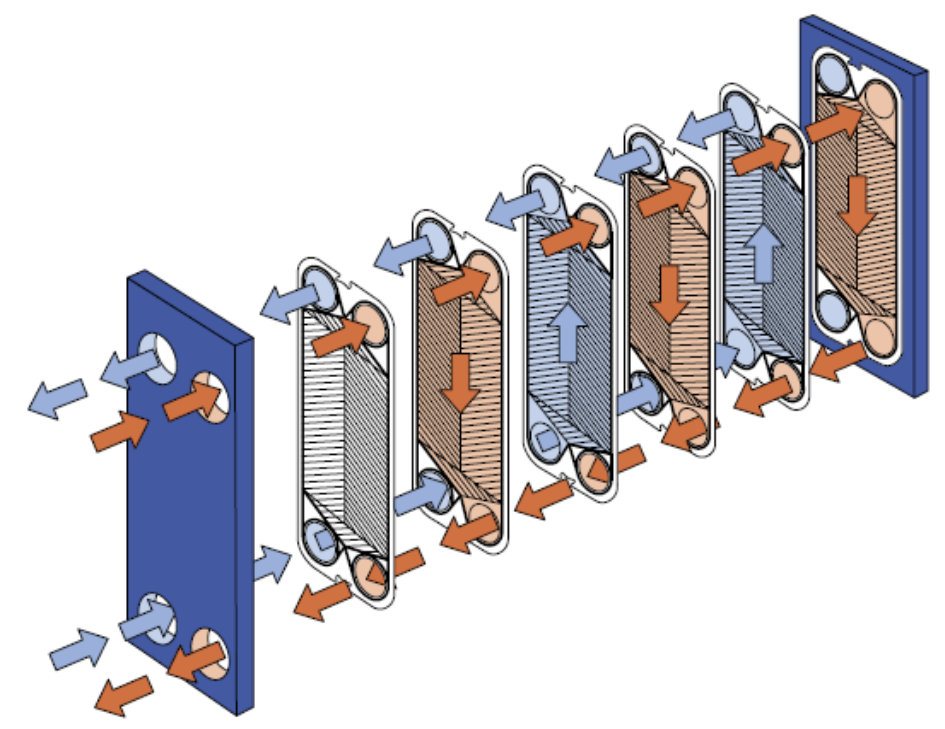

Figura 2-3: Exemplo de escoamento dos fluidos dentro de um PHE (ALFA LAVAL, 2012). 
A configuração de um PHE pode ser descrita de acordo com seus parâmetros mais importantes, que são o número de canais $(N c)$, número de passes do lado I $\left(P^{\prime}\right)$ que contém os canais ímpares, o número de passes do lado II $\left(P^{\prime /}\right)$ que apresenta os canais pares. O parâmetro $\phi$ determina a localização relativa entre conexões de alimentação. $Y_{h}$ é o parâmetro binário que indica qual lado do trocador recebe o fluido quente: para $Y_{h}=1$ o fluido quente escoa através dos canais do lado I e $Y_{h}=0$, caso contrário. Por último tem-se o parâmetro binário que descreve como o fluido escoa dentro de cada canal $\left(Y_{f}\right)$ : para $Y_{f}=1$, o fluido escoa diagonalmente no canal e para $Y_{f}=0$, o escoamento é vertical (GUT, 2003). Esses parâmetros são mostrados na Figura 2-4.
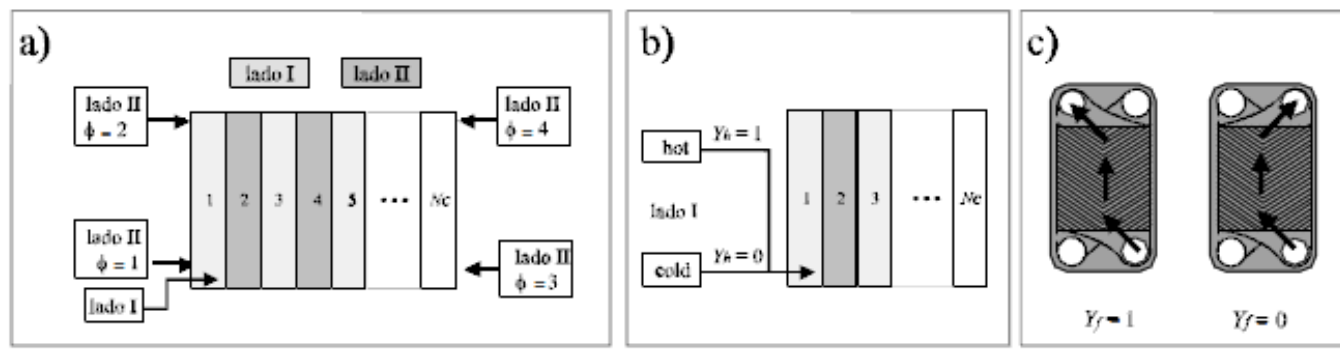

Figura 2-4: Esquema com os parâmetros para descrição da configuração de um trocador de calor a placas (GUT, 2003)

Segundo Wang et al. (2007), devido às suas características estruturais, os trocadores de calor a placas oferecem uma grande quantidade de vantagens em relação aos tradicionais trocadores de calor casco e tubo, o que torna esse equipamento muito competitivo. Algumas dessas vantagens são:

- A corrugação da superfície das placas promove uma maior transferência de calor por meio de diversos mecanismos, como a presença de redemoinhos e vórtices, passagens de fluxo com pequeno diâmetro hidráulico e área de troca térmica efetiva elevada. Os coeficientes de troca térmica são significativamente maiores do que os de trocadores do tipo casco e tubo.

- PHEs apresentam normalmente tamanhos físicos menores devido aos elevados valores de coeficientes de transferência térmica. Para a mesma área efetiva de transferência de calor, a massa e o volume dos trocadores a 
placas são aproximadamente $30 \%$ e $20 \%$, respectivamente, dos valores para trocadores casco e tubo.

- Devido ao arranjo contracorrente e valores elevados de coeficientes de troca térmica, os trocadores de calor a placas são capazes de operar sobre condições de pequenas diferenças de temperaturas entre o produto e 0 fluido de utilidade (aproximadamente $1^{\circ} \mathrm{C}$ ). Até $90 \%$ do calor pode ser recuperado, muito superior aos $50 \%$ alcançado pelo casco e tubo.

- Cada fluido é confinado em canais entre placas com gaxetas. O espaço entre as gaxetas está em contato com a atmosfera, eliminando a possibilidade de contaminação de fluidos caso haja vazamento.

- A inspeção, limpeza, troca de gaxetas e condições higiênicas para processamento de alimentos podem ser facilmente obtidas e conduzidas.

- Placas com diferentes padrões de superfície podem ser combinadas em um único PHE. Essa flexibilidade permite melhor otimização de condições de operação do trocador.

- Apenas as extremidades das placas estão expostas à atmosfera. A perda de calor é desprezível e geralmente não se necessita isolamento térmico.

A principal desvantagem, no entanto, é que o PHE é limitado para aplicações em temperaturas e pressões relativamente baixas. Essas limitações existem principalmente devido às restrições impostas pelo material das gaxetas, que não suportam altas temperaturas e pressões ou a corrosividade de alguns fluidos.

\subsection{Cinética de inativação térmica}

O número de ciclos logarítmicos reduzidos, considerando a população de micro-organismos ou a atividade enzimática, representa a letalidade de um processo térmico. Para uma população de micro-organismos, sobre a influência de uma temperatura letal constante, o decréscimo no número de organismos viáveis por unidade de volume ou massa, geralmente obedece a uma cinética de primeira ordem (FELLOWS, 2000). 
O balanço mássico de uma espécie $A$ (micro-organismo, atividade enzimática ou atributo de qualidade) considerando cinética de primeira ordem, é dado pela Equação (2-1) (TOLEDO, 1999):

$$
\frac{d C_{A}}{d t}=-k \cdot C_{A}
$$

em que $k$ é a constante cinética da reação de inativação térmica $\left[\mathrm{s}^{-1}\right], t$ é 0 tempo de processo [s] e $C_{A}$ é a concentração da espécie $\mathrm{A}$ como, por exemplo, um micro-organismo específico [UFC $/ \mathrm{m}^{3}$ ], sendo UFC unidades formadoras de colônia.

O tempo de processo necessário para que o número inicial de microorganismos seja reduzido em $90 \%$, a uma temperatura constante, é chamado de tempo de redução decimal e é representado pelo parâmetro $D$, e relacionado com a temperatura pela Equação (2-2):

$D=D_{\text {ref }} 10^{\left(\frac{T_{r e f}-T}{z}\right)}$

sendo, $D_{\text {ref, }}$ o tempo de redução decimal a uma temperatura de referência [s],

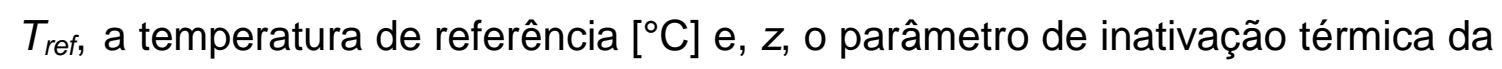
espécie em questão $\left[{ }^{\circ} \mathrm{C}\right]$ que representa o quanto o tempo de redução decimal $D$ é dependente da temperatura, indicando a variação de temperatura necessária para ocasionar uma variação de 10 vezes no valor de $D$ (TOLEDO, 1999).

\subsection{Micro-organismo ou enzima alvo}

Para o dimensionamento de um processo térmico, geralmente escolhese o micro-organismo patogênico mais termoresistente ou uma enzima indesejada como alvo do tratamento térmico.

Tribess (2003) estudou a cinética de inativação térmica da enzima pectinesterase no suco de laranja por meio de processamentos térmicos 
contínuos. No suco fresco ou subpasteurizado a pectinesterase desesterifica a pectina (enzima responsável pela estabilização da turbidez dos sucos cítricos), produzindo metanol e pectina com baixa metoxilação, que precipita, resultando na perda de turbidez e afetando seriamente a qualidade do suco. Foi observado que ocorreu uma maior inativação da enzima com o aumento da temperatura de processamento e com o aumento do tempo de retenção.

Um exemplo de micro-organismo patogênico que é alvo do tratamento térmico é a bactéria Coxiella burnetii. Ela pode estar presente no leite e é conhecida como causadora da febre $Q$, responsável por dores musculares, dores de cabeça intensas, anorexia e febre (MARTH; STEELE, 2001).

Para se quantificar o impacto do processo térmico sobre um atributo de segurança ou de qualidade, pode-se escolher uma enzima como espécie alvo do tratamento térmico. No caso de uma contagem microbiológica custosa e demorada opta-se pela avaliação da presença de uma enzima, suscetível à inativação na pasteurização, presente no produto a ser tratado. Uma dessas possíveis enzimas é a fosfatase alcalina (ALP, EC 3.1.3.1), que está presente no leite e tem a resistência térmica ligeiramente superior aos patógenos formadores de esporos. O rigor do processo térmico aplicado para inativação da ALP é maior do que para a destruição da bactéria alvo na pasteurização do leite, a Coxiella burnetii. Dessa forma, utilizando-se a ALP como enzima alvo também se garante que o leite está livre de organismos patogênicos (FOX; McSWEENEY, 1998).

\subsection{Modelagem e simulação do processo HTST em trocador a placas}

Georgiadis et al. (1998a) realizaram a otimização simultânea dos dados de projeto e operação de trocadores de calor casco e tubo em que ocorre a incrustação de leite, sendo que o modelo adotado é descrito por equações algébricas, diferenciais e diferenciais parciais. Devido a essa alta complexidade do equacionamento e sua natureza, o maior problema verificado pelos autores foi o alto custo computacional para a solução e otimização do problema. Os parâmetros determinados pela otimização incluem o comprimento e o diâmetro 
do trocador, o controle de operação e a sequência das operações chaves. Adotou-se uma função objetivo econômica acompanhada de um grande número de restrições. A otimização do modelo explicitou que o fator de custo devido à interrupção da produção é o mais influente, enquanto que um aumento no consumo de energia devido à incrustação não é muito relevante. Para cada valor de demanda térmica existe um trocador de calor de tamanho ótimo que equilibra a redução dos custos operacionais e incrustação com os custos para projetar o equipamento (Fryer, $1989^{1}$ apud Georgiadis et al., 1998a).

É importante verificar os fatores que acarretam em custos extras de capital durante a operação do trocador de calor. Segundo Garett et al. (1985) esses gastos incluem: aumento de custo devido ao equipamento estar superprojetado, tempo adicional de parada para manutenção e reparo, perda de produção, limpeza de equipamento e desperdícios de energia e calor.

Apesar da complexidade do modelo que descreve a pasteurização em trocadores de calor casco e tubo, Georgiadis et al. (1998b) o simularam com sucesso a troca térmica usando a ferramenta gPROMS, que é um software de modelagem de processos capaz de simular, otimizar e estimar parâmetros de processos altamente complexos. Foi possível verificar uma boa conformidade entre os resultados da simulação, obtidos pela solução de estimativa dinâmica de parâmetros, com dados experimentais.

Georgiadis et al. (2000) também apresentaram a modelagem matemática e simulação de arranjos complexos de PHEs. O equacionamento das reações de incrustração foi acoplado a um modelo geral termodinâmico de trocadores de calor a placas. A simulação buscou adquirir informações significantes sobre os fatores chave que afetam a incrustação do leite. Os resultados da simulação apresentaram-se de acordo com as verificações experimentais e o efeitos das condições iniciais do processo (concentração inicial de proteína ou condições de escoamento) também foram investigados e comparados com valores experimentais e, assim, possibilitou a verificação de maneiras de reduzir os efeitos negativos da incrustação.

\footnotetext{
${ }^{1}$ FRYER, P.J. The uses of fouling models in the design of food process plant. J. Soc. of Dairy Technol., 42, 23, 1989
} 
Georgiadis et al. (2000) se basearam nos resultados dinâmicos para afirmarem que a incrustação não é severa, se comparada ao caso dos trocadores de calor tubulares, em termos da temperatura de saída do leite devido às intensas interações térmicas entre os canais do PHE e ao comportamento "auto-corretivo", podendo assim indicar que os principais gargalos da operação são as restrições de queda de pressão devido ao bloqueio dos canais e não a disponibilidade de calor, como nos casos dos trocadores de casco e tubo. Os modelos, mesmo sendo altamente complexos, foram simulados com sucesso usando a ferramenta gPROMS e podem fornecer base para desenvolver estratégias de controle de otimização em arranjos complexos de PHEs.

Gut (2003) estudou o problema de modelagem e otimização da configuração de operação de um trocador de calor a placas para determinar a distribuição de temperatura em um pasteurizador a placas, usado para o processamento HTST de leite. Neste caso, para um trocador de 124 canais, sem validação experimental e assumindo escoamento pistonado, foi verificado um significativo sobreprocessamento do leite devido à distribuição de temperatura dentro do trocador de calor e condições não isotérmicas do tubo de retenção. 


\section{MODELAGEM MATEMÁTICA}

Neste capítulo é desenvolvida a modelagem matemática de um processo de pasteurização composto por trocador de calor a placas dividido em três seções (Figura 2-1), operando em estado estacionário com fluidos incompressíveis sem mudança de fase.

Ao entrar no PHE, o fluxo é dividido entre os canais que formam o primeiro passe. O fluido escoa então por dentro dos canais corrugados e ao final do passe ocorre a mistura do fluido. O fluxo segue então para o próximo passe e assim sucessivamente até percorrer todos os passes em um determinado lado do trocador. Utilizando as hipóteses que o fluxo principal é dividido igualmente entre os canais que compõem cada passe, que o escoamento é pistonado e ao final de um passe ocorre a mistura perfeita dos fluxos que deixam seus canais, considera-se que a vazão mássica $W$ de alimentação de um fluido seja distribuída uniformemente entre os $N$ canais que compõem o passe. Portanto, é possível calcular a vazão do fluido por canal, $W_{i}$ $(i=1,2, \ldots, N c)$ conforme Equação (3-1) e Equação (3-2):

$W_{i}=\frac{W^{I}}{N^{I}} \quad$ se $i$ é ímpar (canal pertence ao lado I)

$W_{i}=\frac{W^{I I}}{N^{I I}} \quad$ se ié par (canal pertence ao lado II)

sendo, $W$,' a vazão mássica no lado I [kg/s] do trocador e, $W^{\prime \prime}$, a vazão mássica no lado II, e, $N^{\prime}$ e $N^{\prime \prime}$, os números de canais dos lados I e II, respectivamente.

Devido às ranhuras das placas, a turbulência no escoamento dentro dos canais é alta e consequentemente a transição para o regime turbulento de escoamento ocorre em valores mais baixos de Reynolds, podendo assim ser possível assumir o perfil de velocidade dentro do canal como achatado (pistonado).

A modelagem matemática é composta por duas partes principais: modelagem da distribuição de temperatura e modelagem da distribuição de letalidade. Ambas foram desenvolvidas em duas etapas: para os canais das 
três seções do trocador de calor e para o tubo de retenção e suas conexões de entrada e de saída.

\subsection{Distribuição de temperatura}

Para modelar a distribuição de temperatura nos canais do trocador de calor a placas foram utilizadas as seguintes considerações: o processo ocorre em regime permanente, não há troca de calor com o ambiente, não ocorre troca térmica na direção do escoamento, o escoamento é pistonado dentro dos canais, ocorre distribuição uniforme do fluido nos canais, a mistura do fluido é perfeita no fim do passe, não ocorrem mudanças de fase e as propriedades dos fluidos são uniformes na seção.

Para o tubo de retenção e as suas conexões de entrada e saída foram levadas em conta as mesmas hipóteses adotadas para o trocador de calor, com exceção da consideração de que não ocorre troca de calor com o ambiente.

De acordo com as hipóteses de que as trocas de calor com o ambiente nos canais do trocador de calor sejam desprezíveis, que não ocorram mudanças de fase, que as propriedades físicas dos fluidos sejam constantes e que o PHE opere em regime permanente, pode-se afirmar que a taxa de calor trocado, $Q$, é igual às taxas de calor recebido pela corrente fria, $Q_{c o l d}$, e liberado pela corrente quente, $Q_{\text {hot, }}$ conforme a Equação (3-3), utilizando os valores médios dos calores específicos dos fluidos:

$$
Q=\left\{\begin{array}{c}
Q_{\text {hot }}=W_{\text {hot }} \cdot C p_{\text {hot }} \cdot\left(T_{\text {hot }, \text { in }}-T_{\text {hot }, \text { out }}\right) \\
Q_{\text {cold }}=W_{\text {cold }} \cdot C p_{\text {cold }} \cdot\left(T_{\text {cold , in }}-T_{\text {cold ,out }}\right)
\end{array}\right.
$$

em que, $C p$, é o calor específico médio do fluido [J/(kg.K)].

Tendo como referência os lados I e II do trocador, a Equação (3-3) pode ser escrita na forma da Equação (3-4). 


$$
Q=\left\{\begin{array}{l}
Q^{I}=W^{I} \cdot C p^{I} \cdot\left|T_{\text {in }}^{I}-T_{\text {out }}^{I}\right| \\
Q^{I I}=W^{I I} \cdot C p^{I I} \cdot\left|T_{\text {in }}^{I I}-T_{\text {out }}^{I I}\right|
\end{array}\right.
$$

O cálculo dos valores médios dos calores específicos para cada fluido é dado pela Equação (3-5):

$$
\begin{aligned}
& C p_{\text {hot }}=\frac{C p\left(T_{\text {hot }, \text { in }}\right)+C p\left(T_{\text {hot }, \text { out }}\right)}{2} \\
& C p_{\text {cold }}=\frac{C p\left(T_{\text {cold }, \text { in }}\right)+C p\left(T_{\text {cold }, \text { out }}\right)}{2}
\end{aligned}
$$

A Equação (3-6) define o coeficiente global de troca térmica no trocador, $U$, que relaciona a convecção, a condução e a incrustação. Os parâmetros $h_{h o t}$ e $h_{\text {cold }}$ são os coeficientes convectivos de troca térmica e os parâmetros $R_{f, h o t}$ e $R_{f, \text { cold }}$ são os fatores de incrustação dos fluidos quente e frio. Os parâmetros $\varepsilon_{\mathrm{p}}$ e $k_{p}$ são a espessura e a condutividade térmica das placas, respectivamente.

$$
\frac{1}{U}=\frac{1}{h_{\text {hot }}}+\frac{1}{h_{\text {cold }}}+\frac{\varepsilon_{\mathrm{p}}}{k_{p}}+R_{f, \text { hot }}+R_{f, \text { cold }}
$$

\subsubsection{Troca térmica nos canais}

De acordo com Gut (2003), o modelo é desenvolvido a partir do balanço diferencial de energia dentro de cada canal do PHE, levando em conta o volume de controle de dimensões $b, w$ e $\mathrm{d} x$ como mostra a Figura 3-1. A variação da energia do fluido atravessando o volume de controle será igual ao calor trocado com os dois canais adjacentes. A troca térmica ocorre através dos elementos de área $d A p=\Phi . w . d x$ em cada lado do volume. Em que $\Phi$ é o fator de alargamento da área da placa e, $A_{p}$, é a área de troca térmica de uma 
placa do trocador [ $\left.\mathrm{m}^{2}\right]$. Desprezando variações de energia cinética e potencial, o balanço diferencial de energia térmica é mostrado na Equação (3-7).

$$
\begin{aligned}
& W_{i} \cdot C p_{i} \cdot\left(T_{i}(x)-T_{i}(x+\partial x)\right)+ \\
& \partial A_{p} \cdot U_{i-1} \cdot\left[\left(T_{i-1}(x)-T_{i}(x)\right)+\left(T_{i+1}(x)-T_{i}(x)\right)\right]=0
\end{aligned}
$$

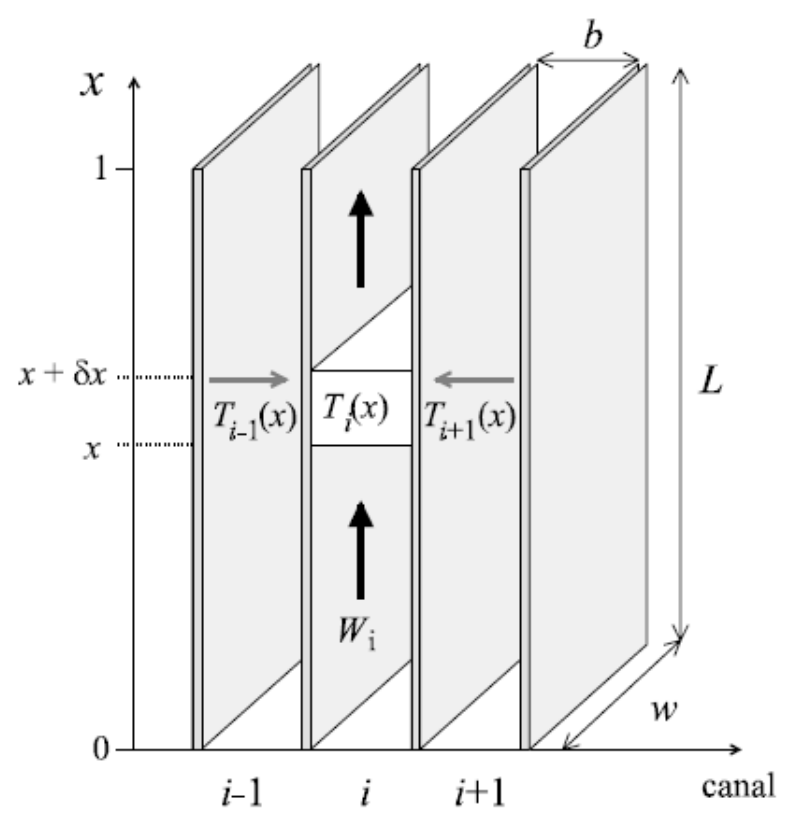

Figura 3-1: Esquema do volume de controle usado para o balanço diferencial de energia no canal do trocador de calor (GUT, 2003).

Convertendo a Equação (3-7) para o formato diferencial e adicionando a variável $s_{i}(+1$ ou -1$)$, que indica o sentido de escoamento dentro do canal, temse a Equação (3-8), representando o balanço energético em um canal qualquer do trocador:

$\frac{d T_{i}}{d x}=\frac{s_{i} \cdot w \cdot \Phi \cdot U_{i-1}}{W_{i} \cdot C p_{i}} \cdot\left(T_{i-1}-T_{i}\right)+\frac{s_{i} \cdot w \cdot \Phi \cdot U_{i}}{W_{i} \cdot C p_{i}} \cdot\left(T_{i+1}-T_{i}\right)$

em que, $C p_{i}$ é o calor específico a pressão constante $[\mathrm{J} / \mathrm{kg} . \mathrm{K}], T_{i}$ é a temperatura $[\mathrm{K}], U_{i}$ é o coeficiente global de troca térmica entre canais $i$ e $i+1$ 
$\left[\mathrm{W} / \mathrm{m}^{2} . \mathrm{K}\right]$ e $x$ é a direção tangencial ao escoamento nos canais [m]. O índice i representa o canal.

A variável $x$ é adimensionalizada de acordo com a Equação (3-9):

$$
\eta(x)=\frac{x}{L} \quad, 0 \leq \eta \leq 1
$$

em que, $L$ é o comprimento da placa medido entre as bases dos orifícios [m].

Considera-se que o coeficiente global de troca térmica seja uniforme no trocador e igual a $U$. Desta forma o balanço energético para o primeiro canal é mostrado na Equação (3-10). Para um canal i entre o primeiro e último canal tem-se a Equação (3-11) e Equação (3-12):

$$
\begin{aligned}
& \frac{d T_{i}}{d \eta}=s_{i} \cdot \alpha^{\mathrm{I}} \cdot\left(-T_{1}(\eta)+T_{2}(\eta)\right) \\
& \frac{d T_{i}}{d \eta}=s_{i} \cdot \alpha^{\mathrm{I}} \cdot\left(T_{i-1}(\eta)-2 \cdot T_{i}(\eta)+T_{i+1}(\eta)\right) \quad \text { se i é ímpar } \\
& \frac{d T_{i}}{d \eta}=s_{i} \cdot \alpha^{\mathrm{II}} \cdot\left(T_{i-1}(\eta)-2 \cdot T_{i}(\eta)+T_{i+1}(\eta)\right) \quad \text { se i é par }
\end{aligned}
$$

sendo que, $\alpha^{\prime}$ e $\alpha^{\prime \prime}$ são os coeficientes adimensionais de troca térmica nos lados I e II, respectivamente.

Já para o último canal $(i=N c)$, com $N c$ sendo o número de canais, o equacionamento da distribuição de temperatura pode ser representado pela Equação (3-13) e Equação (3-14). Os coeficientes adimensionais de troca de calor são definidos na Equação (3-15):

$$
\begin{array}{ll}
\frac{d T_{N_{c}}}{d \eta}=s_{N_{c}} \cdot \alpha^{\mathrm{I}} \cdot\left(T_{N_{c}-1}(\eta)+T_{N_{c}}(\eta)\right) & \text { se } N_{c} \text { é ímpar } \\
\frac{d T_{N_{c}}}{d \eta}=s_{N_{c}} \cdot \alpha^{\mathrm{II}} \cdot\left(T_{N_{c}-1}(\eta)+T_{N_{c}}(\eta)\right) & \text { se } N_{\mathrm{c}} \text { é par }
\end{array}
$$


$\alpha^{\mathrm{I}}=\frac{A_{p} \cdot U \cdot N^{I}}{W^{I} \cdot C p^{I}} \quad, \quad \alpha^{\mathrm{II}}=\frac{A_{p} \cdot U \cdot N^{I I}}{W^{I I} \cdot C p^{I I}}$

O coeficiente global de troca térmica, $U_{i}$, definido entre os canais $i$ e $i+1$, é calculado pela Equação (3-16):

$\frac{1}{U_{i}}=\frac{1}{h_{i}}+\frac{1}{h_{i+1}}+\frac{\varepsilon_{\mathrm{p}}}{k_{p}}+R_{f, h o t}+R_{f, \text { cold }}$

Adotando-se a hipótese de que as propriedades físicas dos fluidos sejam constantes, os coeficientes convectivos são constantes para os fluidos quente e frio e a Equação (3-16) se reduzirá à Equação (3-6), considerando que as contribuições dos fatores de incrustação sejam praticamente nulas. Então o coeficiente global de troca térmica será uniforme no trocador e igual a $U$.

Os coeficientes convectivos estão relacionados principalmente com as propriedades termofísicas do fluido assim como com o escoamento e a geometria do trocador e são geralmente calculados a partir da correlação empírica no formato expresso na Equação (3-17):

$N u=a_{1} \cdot \operatorname{Re}^{a_{2}} \cdot \operatorname{Pr}^{a_{3}}$

em que $a_{1}, a_{2}$ e $a_{3}$ são parâmetros numéricos da equação de Nusselt.

As variáveis adimensionais Reynolds $(R e)$, que é a relação entre as forças de inércia e viscosas; Prandtl $(P r)$, que é a relação entre a difusividade de momento e a térmica; Nusselt $(N u)$, que representa o gradiente de temperatura adimensional na interface fluido-superfície, são definidas na Equação (3-18):

$$
N u=\frac{h \cdot d_{e}}{k} ; \quad \quad R e=\frac{d_{e} \cdot v \cdot \rho}{\mu} ; \quad \operatorname{Pr}=\frac{C p \cdot \mu}{k} ;
$$


em que $d_{e}$ é o diâmetro equivalente [m], $h$ é o coeficiente convectivo de troca térmica $\left[\mathrm{W} / \mathrm{m}^{2} . \mathrm{K}\right], k$ é a condutividade térmica $[\mathrm{W} / \mathrm{m} . \mathrm{K}], v$ é a velocidade média de escoamento no canal [m/s], $\rho$ é a densidade $\left[\mathrm{kg} / \mathrm{m}^{3}\right]$ e $\mu$ é a viscosidade [Pa.s].

Os valores dos parâmetros $a_{1}, a_{2}$ e $a_{3}$ podem ser obtidos experimentalmente através do ajuste de parâmetros (GALEAZZO et al., 2006).

$\mathrm{O}$ diâmetro equivalente do canal do $\mathrm{PHE}, d_{e}$, é dado pela Equação (3-19) (GUT, 2003):

$d_{e}=\frac{2 . b}{\Phi}$

São apresentadas, nas Equações (3-20) a (3-23), as correlações para determinação das propriedades termofísicas da água. As propriedades mostradas a seguir, densidade $\rho\left[\mathrm{kg} / \mathrm{m}^{3}\right]$, viscosidade $\mu[\mathrm{Pa} . \mathrm{s}]$, calor específico $C p \quad[\mathrm{~J} / \mathrm{kg} . \mathrm{K}]$ e condutividade térmica $k$ [W/K.m] são calculadas com temperaturas $T$ [K] (RAHMAN, 1995):

$\rho=0,208 \cdot 10^{-4} \cdot T^{3}-0,6668 \cdot 10^{-2} \cdot T^{2}+0,04675 \cdot T+999,9$

$\mu=\frac{1}{21,482\left[(T-8,435)+\sqrt{8078,4+(T-8,435)^{2}}\right]-1200}$

$C p=0,52013 \cdot 10^{-6} \cdot T^{4}-0,21528 \cdot 10^{-3} \cdot T^{3}+\cdots$

$0,041758 . T^{2}-2,6171 . T+4227,1$

$k=0,5692+\frac{T}{538}-\frac{T^{2}}{133333}$ 
Para a solução numérica do sistema de equações do balanço energético no trocador são necessárias as equações para condições de contorno para a temperatura $T_{i}(\eta)$ em cada canal. As principais hipóteses adotadas para a determinação destas equações são a de distribuição uniforme de vazão entre os canais de um passe e de mistura perfeita do fluido ao término de um passe. Tomando por exemplo a configuração de um trocador como mostra a Figura 3-2, a Equação (3-24) apresenta as equações de condição de contorno para o lado I (frio) e a Equação (3-25) apresenta as equações de condição de contorno para o lado II (quente).
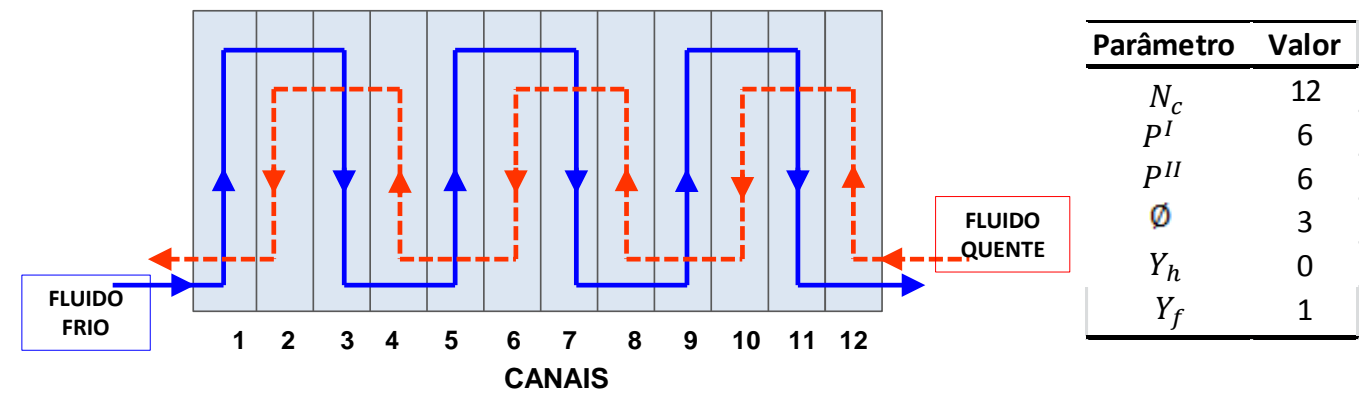

Figura 3-2: Exemplo de um arranjo em série de um PHE com 12 canais (GUTIERREZ, 2012).

$$
\begin{aligned}
& T_{1}(\eta=0)=T_{\text {cold,in }} \\
& T_{3}(\eta=1)=T_{1}(\eta=1) \\
& T_{5}(\eta=0)=T_{3}(\eta=0) \\
& T_{7}(\eta=1)=T_{5}(\eta=1) \\
& T_{9}(\eta=0)=T_{7}(\eta=0) \\
& T_{11}(\eta=1)=T_{9}(\eta=1) \\
& T_{\text {cold,out }}=T_{11}(\eta=0)
\end{aligned}
$$

$$
\begin{aligned}
& T_{\text {hot,out }}=T_{2}(\eta=0) \\
& T_{2}(\eta=1)=T_{4}(\eta=1) \\
& T_{4}(\eta=0)=T_{6}(\eta=0) \\
& T_{6}(\eta=1)=T_{8}(\eta=1) \\
& T_{8}(\eta=0)=T_{10}(\eta=0) \\
& T_{10}(\eta=1)=T_{12}(\eta=1) \\
& T_{12}(\eta=0)=T_{\text {hot,in }}
\end{aligned}
$$


As condições de contorno para temperatura do fluido podem ser escritas na seguinte forma geral:

- Condição para entrada de fluido no canal (a temperatura no início do primeiro passe é igual à de alimentação do fluido no trocador):

$T_{i}(\eta)=T_{\text {fluido, in }} \quad, \mathrm{i} \in$ ao primeiro passe

- Condição de contorno que contempla a mudança de passe (ocorre a mistura perfeita do fluido que deixa o passe anterior, antes de entrar no próximo). A temperatura de saída do passe é igual à somatória das temperaturas de saída dos canais dividido pelo número de canais que conformam o passe $(N)$ :

$T_{i}(\eta)=\frac{1}{N} \sum_{\substack{j \in \text { passe } \\ \text { anterior }}}^{N} T_{j}(\eta) \quad, \mathrm{i} \in$ ao novo passe

É necessário definir a temperatura de saída do fluido do último passe. Para isso tem-se a Equação (3-28):

$T_{\text {fluido out }}=\frac{1}{N} \sum_{\substack{j \in \text { ulttimo } \\ \text { passe }}}^{N} T_{j}(\eta)$ 


\subsubsection{Troca térmica no tubo de retenção e conexões}

O balanço de energia realizado no tubo de retenção e nas duas conexões, localizadas antes e depois da retenção, é realizado a partir do volume de controle apresentado na Figura 3-3.
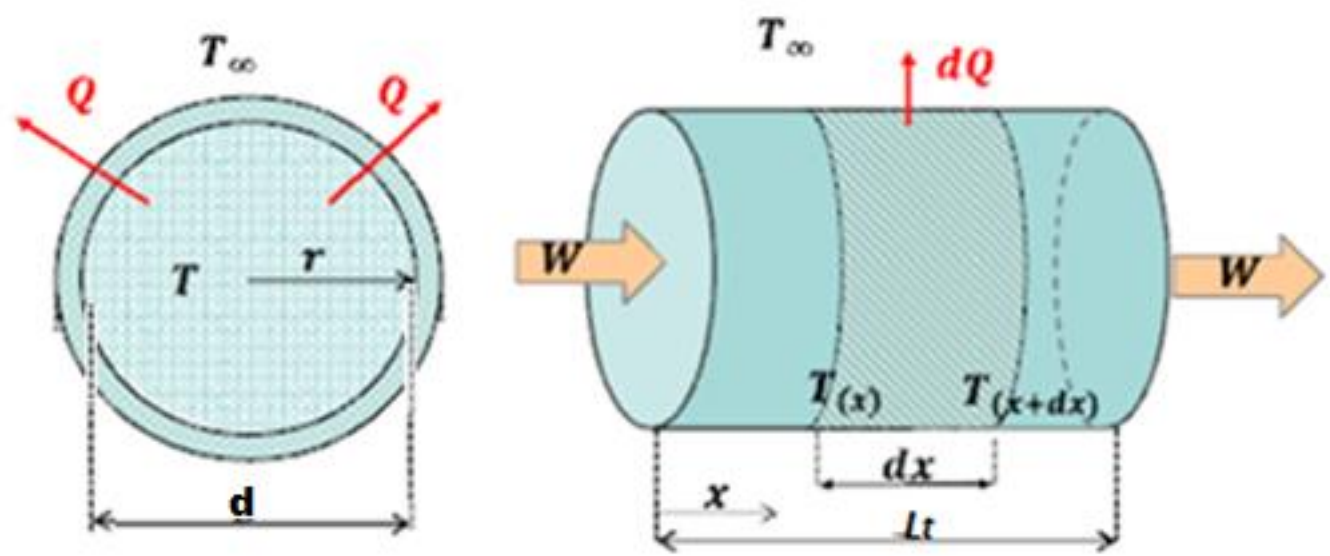

Figura 3-3: Volume de controle para o balanço de energia nos tubos (GUTIERREZ, 2012).

O modelo do balanço de energia para os tubos é mostrado na Equação (3-29):

$W \cdot C p \cdot(T(x)-T(x+d x))-\pi \cdot d \cdot L_{t} \cdot U_{t} \cdot\left(T(x)-T_{\infty}\right)=0$

em que $L_{t}$ é o comprimento do tubo ou trecho do tubo [m], $U_{t}$ o coeficiente global de troca térmica entre o fluido e o ambiente $\left[\mathrm{W} / \mathrm{m}^{2} . \mathrm{K}\right]$, $d$ é o diâmetro interno [m] e $T_{\infty}$ a temperatura ambiente [K].

Convertendo a Equação (3-29) para o formato diferencial e adimensionalizando a variável $x$, da mesma maneira como na Equação (3-9), tem-se a Equação (3-30), representando o balanço energético em um trecho tubular: 
$\frac{d T}{d \eta}+\frac{\pi \cdot d \cdot L_{t} \cdot U_{t}}{W \cdot C p} \cdot\left(T(\eta)-T_{\infty}\right)=0$

Nesse caso, a condição de contorno adotada para integração da Equação (3-30) é que a temperatura de entrada de um trecho de tubo ou do tubo de retenção seja igual a de saída da etapa imediatamente anterior.

\subsection{Distribuição de letalidade}

Para a modelagem da distribuição de letalidade no PHE e nos tubos foi considerado que o escoamento seja pistonado, que a operação ocorra em estado estacionário e a destruição do indicador alvo (enzima ou microorganismo) siga uma cinética de primeira ordem.

\subsubsection{Letalidade nos canais}

Para uma operação contínua nos canais do trocador, no estado estacionário, o balanço molar de uma espécie A genérica é dado pela Equação (3-31) (FOGLER, 1999):

$q \frac{d C_{A}}{d V}=r_{A}$

em que $r_{A}$, é a velocidade de reação $\left[\mathrm{mol} / \mathrm{m}^{3} . \mathrm{s}\right], V$ é o volume $\left[\mathrm{m}^{3}\right], C_{A}$ é a concentração da espécie $A\left[\mathrm{~mol} / \mathrm{m}^{3}\right]$ e $q$ é a vazão volumétrica $\left[\mathrm{m}^{3} / \mathrm{s}\right]$.

Para $r_{A}=-k . C_{A}$, em que, $k$ é a velocidade específica da reação, que no caso de um processo térmico é a constante de primeira ordem de inativação da espécie $\mathrm{A}$ (que pode ser uma enzima ou micro-organismo), e para $d V=A . d x$, tem-se a Equação (3-32): 
$\frac{d C_{A}}{d x}=-\left(\frac{1}{V} \cdot k \cdot C_{A}\right)$

em que, $v$ é a velocidade média de escoamento no canal [m/s] e $A$ a área da seção transversal do escoamento [m²].

A equação que relaciona a constante cinética da reação $k$ e o valor de $D$ é dada pela Equação (3-33).

$k=\frac{\ln (10)}{D}=\frac{2,303}{D}$

O efeito da temperatura do processo sobre o parâmetro cinético é descrito pela Equação (2-2) (TOLEDO, 1999).

Substituindo as Equações (3-33) e (2-2) na Equação (3-32), usando a variável $x$ adimensionalizada $(\eta(x)=x / L)$ e explicitando o sentido de escoamento do fluido, tem-se a Equação (3-34):

$$
\frac{d C_{A i}}{d \eta}=-\frac{L}{V} \cdot\left(\frac{2,303 \cdot C_{A i}(\eta)}{D_{\text {ref }} 10^{\left(\frac{T_{r e f} T}{Z}\right)}}\right) \cdot S_{i}
$$

em que, $1 \leq i \leq N_{C}$ e para as seções de aquecimento e resfriamento, o contador $i$ só assume valores referentes aos canais do produto e para a seção de regeneração assume valores pares e ímpares. As condições de contorno adotadas são análogas às usadas para a modelagem de temperatura, mas em termos de concentração.

No estudo dos PHEs, assume-se que o fluxo seja uniformemente distribuído nos canais de um passe. Juntamente com a consideração de escoamento pistonado, plug flow ideal, o tempo médio de residência pode ser tomado como sendo igual ao tempo espacial, $\tau$, que é definido pela Equação (3-35) (LEVENSPIEL, 2007). 
$\tau=\frac{V}{q}=\frac{A \cdot L}{A \cdot V}=\frac{L}{V}$

O que se observa na prática é que a hipótese de distribuição uniforme de fluxo no passe pode não ser realista na prática. A distribuição do fluxo dentro dos PHEs foi investigada experimentalmente por Bobbile et al. (2006) e Tareda et al. (2007), e usando CFD (Computational Fluid Dynamics) por Fernandes et al. (2005), Galeazzo et al. (2006) e Han et al. (2010). De maneira mais rigorosa, o fluxo dentro dos canais é avaliado pela distribuição do tempo médio de residência.

O valor de esterilização (SV) ou decaimento decimal da concentração é verificado para analisar a eficiência e letalidade alcançada no processo de pasteurização em relação à queda na contagem de número do microorganismo alvo no produto a ser tratado, ou seja, pelo decaimento decimal que é dado pela Equação (3-36):

$$
S V=\log \left(\frac{C_{A_{0}}}{C_{A}}\right)
$$

em que, $C_{A 0}$ é a concentração inicial de micro-organismo ou enzima [UFC/m³] e $C_{A}$ é a concentração pontual verificada [UFC $\left./ \mathrm{m}^{3}\right] . C_{A}$ pode representar ainda a atividade de uma enzima ou a concentração de um nutriente.

O valor de $C_{A}$ pode ser acompanhado em função da distância percorrida pela variável $\eta$ ou pelo tempo de escoamento, acompanhando uma partícula do fluido. Esse tempo pode ser o tempo médio de residência ou o tempo espacial. 


\subsubsection{Letalidade no tubo de retenção e conexões}

O mesmo equacionamento desenvolvido para os canais do trocador de calor é utilizado para a distribuição de concentração no tubo de retenção e para as duas conexões, porém apenas em um único sentido de escoamento. Assim, tem-se a Equação (3-37):

$$
\frac{d C_{A}}{d \eta}=-\frac{L_{t}}{V} \cdot\left(\frac{2,303 \cdot C_{A}(\eta)}{D_{r e f} \cdot 10^{\left(\frac{T_{r e f}-T}{z}\right)}}\right)
$$

O tempo espacial médio no tubo e nas duas conexões é dado pela Equação (3-38), sendo que o volume interno $V$ é dado pelo volume interno do tubo:

$$
\tau_{\mathrm{t}}=\frac{L_{t}}{V}=\frac{V}{q}
$$

São utilizadas condições de contorno semelhantes às utilizadas para distribuição de temperatura nos tubos, mas focadas para concentração.

Uma alternativa mais realista para representar o escoamento nos canais do trocador ou nos tubos e conexões é substituir o tempo espacial $\tau$ pelo tempo médio de residência $t_{m}$ que é determinado experimentalmente. Sabe-se que $t_{m}$ $<\tau$ devido à existência de zonas de estagnação de fluido (LEVENSPIEL, 2007).

O equacionamento para o tempo médio de residência nas três seções do trocador e no tubo de retenção é específico para o equipamento utilizado no estudo de caso e validação apresentados no presente trabalho. Por essa razão ele será apresentado no capítulo seguinte. 


\section{ESTUDO DE CASO E VALIDAÇÃO}

O modelo do processo de pasteurização em um PHE desenvolvido no Capítulo 3 foi simulado em ambiente gPROMS para que fosse testado em um estudo de caso e feita a análise do seu comportamento e verificação dos resultados.

Nessa seção são mostradas as dimensões das placas do trocador de calor utilizadas na simulação, a configuração do equipamento adotada e suas condições de operação. Tais dimensões foram obtidas do equipamento utilizado no procedimento experimental para validação do modelo.

\subsection{Características do equipamento}

Para a avaliação do modelo térmico e de letalidade desenvolvidos, o processo de pasteurização foi simulado levando em conta as características de um pasteurizador a placas FT-43 (Armfield) de laboratório com placas lisas de aço inoxidável, separadas por gaxetas de silicone, alimentado por uma bomba peristáltica, mostrado na Figura 4-1, na qual podem ser identificadas as três seções do trocador de calor (regeneração, aquecimento e resfriamento) incorporadas em um único pedestal; o tubo de retenção e as duas mangueiras de conexão de silicone e o tanque de alimentação.

As principais características e dimensões das placas do pasteurizador utilizado como exemplo para os estudos de casos são apresentadas na Tabela 4-1 e as dimensões das gaxetas são mostradas na Figura 4-2.

O tubo de retenção está conectado por duas mangueiras, uma de cada lado de suas extremidades. A Tabela 4-2 apresenta os valores de comprimento e diâmetro interno da retenção e das duas conexões, sendo as últimas indicadas como conexão 1 e conexão 2. Nesse equipamento o tubo de retenção é isolado termicamente, pois observou-se perda de calor excessiva do produto processado nessa região. No equipamento industrial o tubo de retenção não é isolado. 


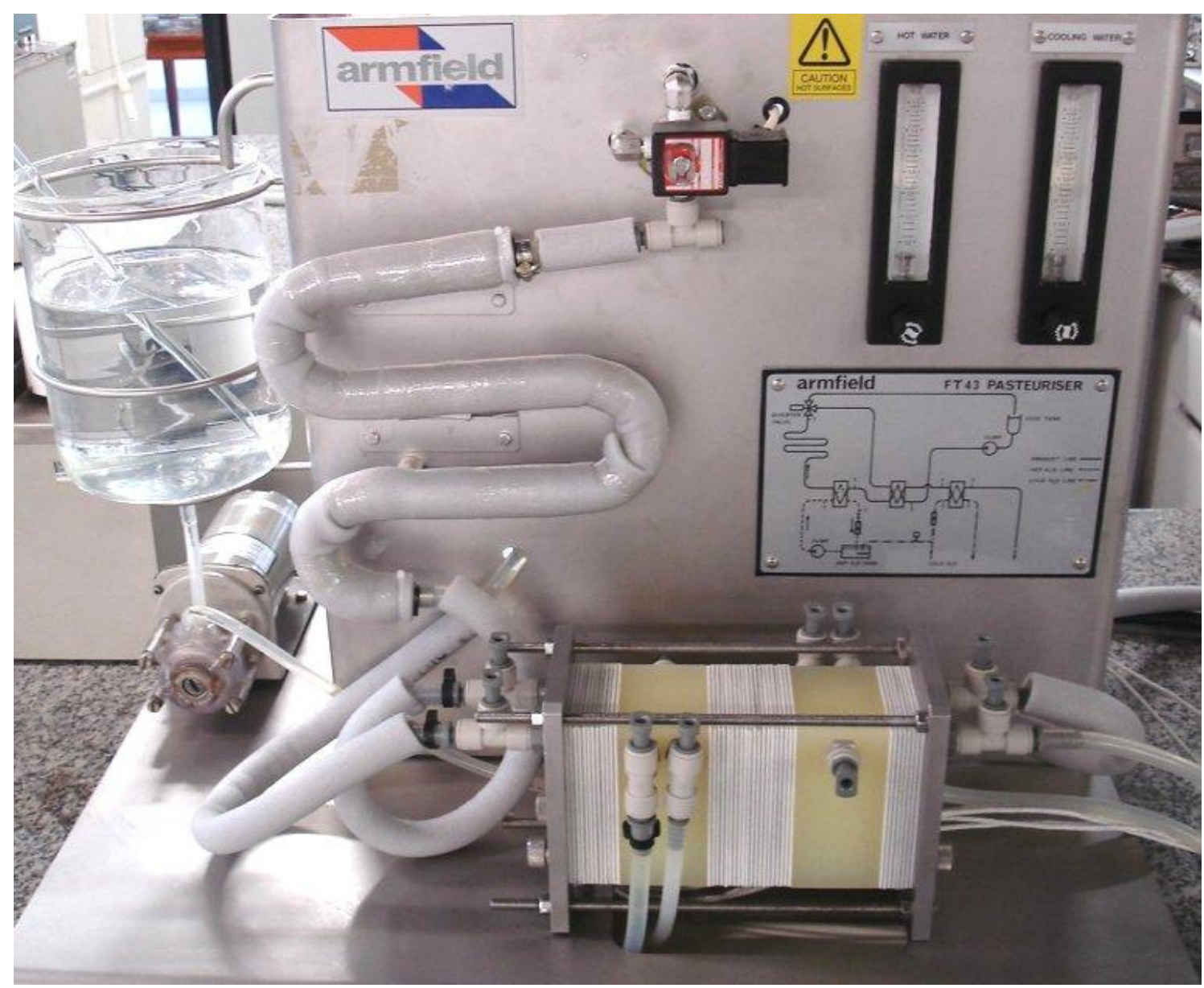

Figura 4-1: Foto do pasteurizador laboratorial FT-43 (Armfield, UK).

Tabela 4-1: Características das placas do trocador de calor (GUTIERREZ, 2012).

\begin{tabular}{lll}
\hline Comprimento da parte úmida, $L$ & $8,35 \cdot 10^{-2}$ & $\mathrm{~m}$ \\
Largura da parte úmida, $w$ & $6,00 \cdot 10^{-2}$ & $\mathrm{~m}$ \\
Espessura do canal, $b$ & $1,50 \cdot 10^{-3}$ & $\mathrm{~m}$ \\
Diâmetro do orifício, $d_{p}$ & $8,00 \cdot 10^{-3}$ & $\mathrm{~m}$ \\
Espessura da placa, $\varepsilon_{p}$ & $1,00 \cdot 10^{-3}$ & $\mathrm{~m}$ \\
Fator de alargamento, $\Phi$ & 1,00 & - \\
Condutividade térmica, $k$ & $1,34.10$ & $\mathrm{~W} / \mathrm{m} \cdot \mathrm{K}$ \\
\hline
\end{tabular}

Na Figura 4-3 estão indicados oito pontos de interesse para a verificação de temperatura do produto no processo simulado além de outros quatro pontos referentes à água de aquecimento e de resfriamento. No equipamento laboratorial, nesses pontos estão localizados sensores de temperatura 
(termopares com junta exposta) que colhem informações de temperatura do fluido naquele ponto, usando um sistema de aquisição de dados (National Instruments).

A descrição e localização de todos os pontos de interesse são mostradas na Tabela 4-3. Na Tabela 4-5 são mostrados os parâmetros da Equação (3-17) para determinação do coeficiente de convecção.

O arranjo das três seções do trocador de calor foi do tipo simétrico em série e contracorrente. Foram utilizados dez passes de um canal na regeneração, seis passes de um canal no aquecimento e quatro passes de um canal no resfriamento. Os principais parâmetros da configuração adotada para a simulação do processo de pasteurização são mostrados na Tabela 4-4.

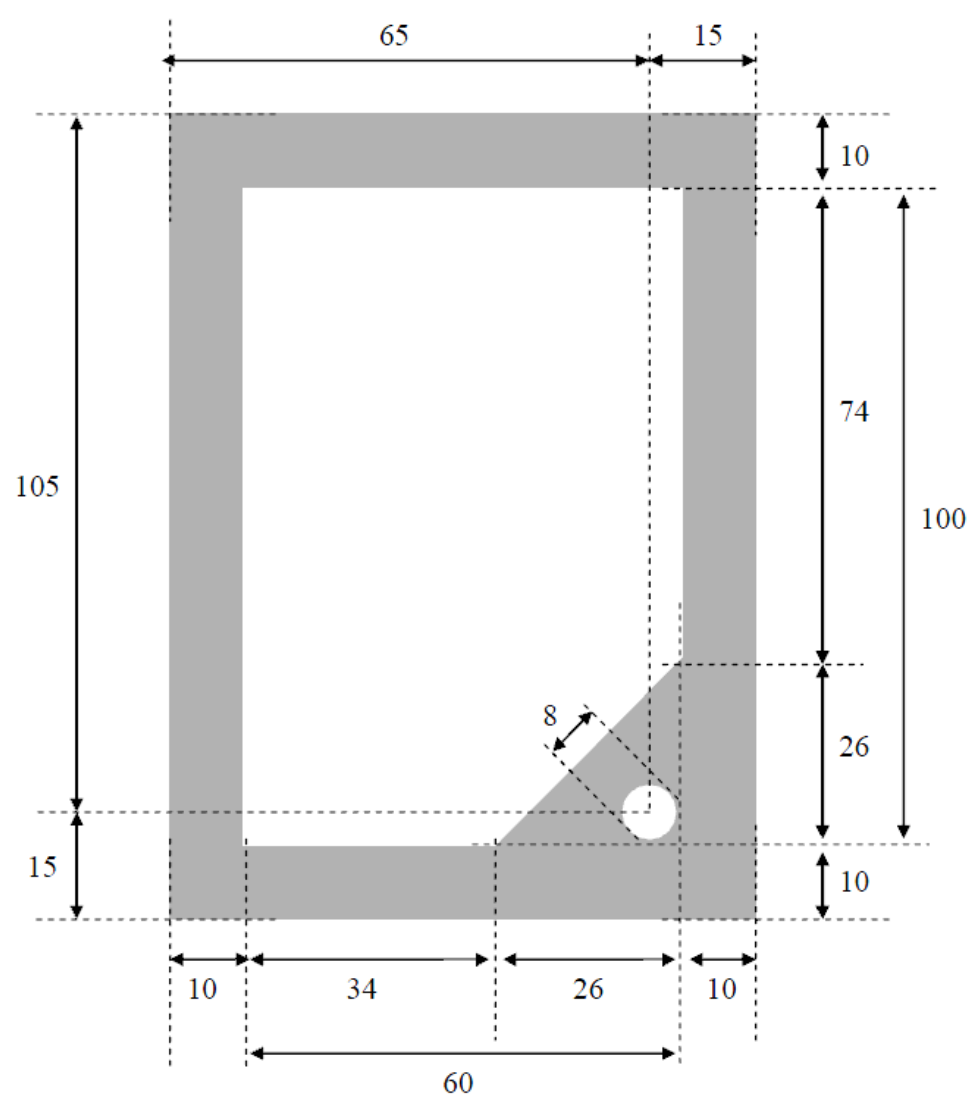

Figura 4-2: Dimensões da gaxeta do trocador de calor a placas (mm) (GUTIERREZ, 2012).

Para a simulação, considerou-se que todos os fluidos presentes no processo foram água destilada e suas propriedades termofísicas foram obtidas a partir da Equação (3-20) à Equação (3-23). 
Tabela 4-2: Características do tubo de retenção e conexões.

\begin{tabular}{lcc}
\hline & Comprimento [m] & Diâmetro interno [mm] \\
\hline Conexão 1 & 0,48 & 9,5 \\
Tubo de retenção & 0,834 & 10,7 \\
Conexão 2 & 1,17 & 6,4 \\
\hline
\end{tabular}

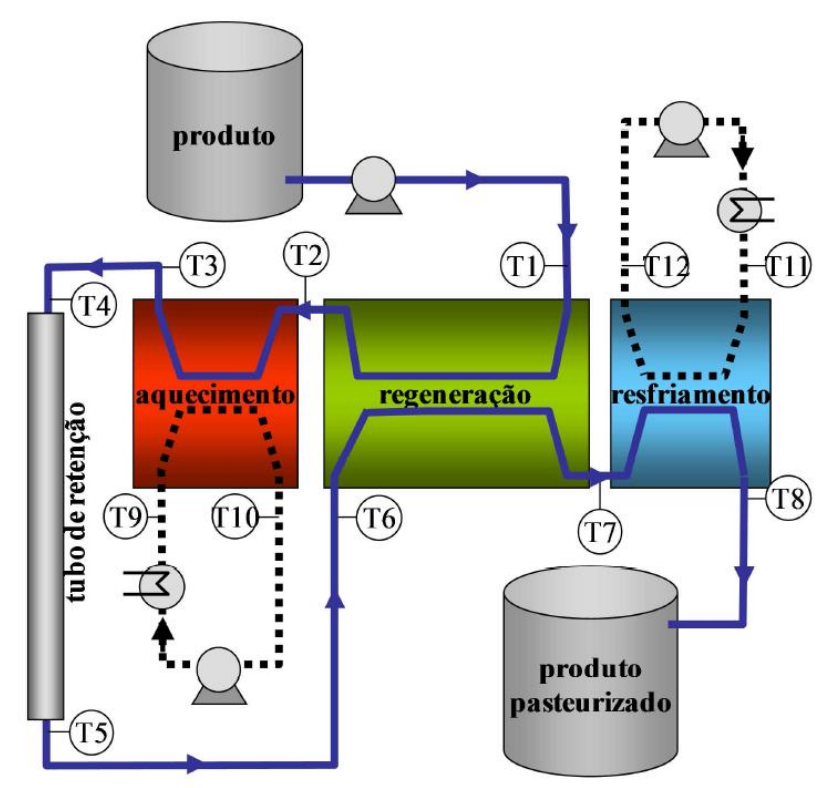

Figura 4-3: Esquema do pasteurizador com pontos de interesse destacados (AGUIAR, 2009).

Tabela 4-3: Descrição da localização dos pontos de interesse do processo de pasteurização.

\begin{tabular}{cl}
\hline Ponto & \multicolumn{1}{c}{ Descrição } \\
\hline T1 & Entrada do produto no processo \\
T2 & Saída da regeneração e entrada para aquecimento \\
T3 & Saída do aquecimento e entrada para o tubo de retenção \\
T4 & Região entre a primeira conexão e o tubo de retenção \\
T5 & Região entre o tubo de retenção e segunda conexão \\
T6 & Saída do tubo de retenção e entrada da regeneraça a regeneração entrada para resfriamento \\
T7 & Saída do processo \\
T8 & Entrada da água de aquecimento \\
T9 & Saída da água de aquecimento \\
T10 & Entrada da água de resfriamento \\
T11 & Saída da água de resfriamento \\
T12 &
\end{tabular}


Tabela 4-4: Principais parâmetros das seções do trocador de calor.

\begin{tabular}{lccc}
\hline \multicolumn{1}{c}{ Parâmetro } & Regeneração & Aquecimento & Resfriamento \\
\hline Número de canais, $N_{c}$ & 20 & 12 & 8 \\
Número de passes (lado I), $P^{\prime}$ & 10 & 6 & 4 \\
Número de passes (lado II), $P^{\prime \prime}$ & 10 & 6 & 4 \\
Posição relativa da conexão de & 3 & 3 & 3 \\
alimentação do lado II, $\phi$ & & 0 & 1 \\
Localização do fluido quente, $Y_{h}$ & 0 & 1 & 1 \\
Tipo de escoamento nos canais, $Y_{f}$ & 1 & & \\
\hline
\end{tabular}

Tabela 4-5: Parâmetros numéricos da equação de Nusselt (AGUIAR, 2009).

$\begin{array}{ll}a_{1} & 9,02 \cdot 10^{-2} \\ a_{2} & 6,63 \cdot 10^{-1} \\ a_{3} & 3,33 \cdot 10^{-1}\end{array}$

Para as três seções do pasteurizador, o volume interno ( $V$ é calculado pela Equação (4-1) segundo Gutierrez et al. (2011), sendo $P$ o número de passes da seção:

$V(m L)=9,20 . P+2,85$

Segundo Gutierrez et al. (2011), o tempo médio de residência é calculado pela Equação (4-2), em que o $V_{p f}$ e $V_{\text {mix }}$ são o volume plug flow e volume de mistura perfeita, respectivamente. A soma desses volumes é inferior ao volume interno do trocador, sendo que essa diferença é considerada como volume morto:

$$
\begin{aligned}
& t_{m}=\frac{V_{p f}+V_{\text {mix }}}{q} \\
& V_{p f}(m L)=0,069 \cdot P^{2}+4,65 . P \\
& V_{\text {mix }}(m L)=-0,0262 \cdot P^{2}+2,16 \cdot P
\end{aligned}
$$


O tempo médio de residência no tubo de retenção é dado pela Equação (4-5), segundo Gutierrez et al. (2010):

$t_{m}=\frac{65,38}{q}$

em que, $q$ é a vazão volumétrica [mL/s] e $t_{m}$ é o tempo médio de residência [s].

A partir das configurações do equipamento utilizado pôde-se determinar o tempo médio de residência e tempo espacial para as três seções do pasteurizador, tubo de retenção e para as duas conexões. Esses valores são mostrados na Tabela 4-6.

Tabela 4-6: Tempo espacial e tempo médio de residência em cada seção do pasteurizador.

\begin{tabular}{|c|c|c|}
\hline & Tempo Espacial (s) & Tempo Médio de Residência (s) \\
\hline Regeneração 1 & 17,1 & 13,0 \\
\hline Aquecimento & 10,5 & 7,6 \\
\hline Conexão 1 & 6,1 & 6,1 \\
\hline Tubo de retenção & 13,5 & 11,8 \\
\hline Conexão 2 & 6,8 & 6,8 \\
\hline Regeneração 2 & 17,1 & 13,0 \\
\hline Resfriamento & 7,1 & 5,0 \\
\hline Total & 78,1 & 63,4 \\
\hline
\end{tabular}

Para conexão 1 e 2 o tempo médio de residência é igual ao tempo espacial, pois o tempo médio de residência não foi determinado experimentalmente. $O$ valor de $t_{m}$ ou $\tau$ em um canal do trocador é obtido dividindo o valor na Tabela 4-6 pelo número de canais $\left(N_{c}\right)$.

Os valores do número de Reynolds nas seções do pasteurizador e nas regiões tubulares são mostrados na Tabela 4-7. 
Tabela 4-7: Número de Reynolds em cada seção do pasteurizador.

\begin{tabular}{lc}
\hline \multicolumn{1}{c}{ Seção } & Reynolds \\
\hline Regeneração 1 & 236 \\
Aquecimento & 441 \\
Conexão 1 & 1643 \\
Tubo de retenção & 1459 \\
Conexão 2 & 2439 \\
Regeneração 2 & 355 \\
Resfriamento & 234 \\
\hline
\end{tabular}

Apesar dos valores baixos de Reynolds nos canais do pasteurizador, a hipótese de que o escoamento pistonado ainda é mantida. Se fosse levado em conta o escoamento laminar, a modelagem matemática desenvolvida teria alto grau de complexidade.

\subsection{Exemplo de Simulação}

Para testar o modelo desenvolvido, foi simulado um processo de pasteurização em que o micro-organismo a ser destruído foi a bactéria Coxiella burnetii que é o alvo do tratamento térmico do leite. O processo foi avaliado levando em conta duas abordagens distintas, uma em que o histórico de temperatura e de letalidade foram verificados de acordo com o tempo médio de residência e outra análise levando em conta o tempo espacial, podendo assim comparar o comportamento das duas abordagens.

Adotou-se a vazão de produto como sendo a de condição nominal do equipamento, $20 \mathrm{~L} / \mathrm{h}$, e vazão de água de aquecimento e de resfriamento de 1,0 L/min. Os parâmetros cinéticos referentes à inativação térmica da Coxiella burnetii são mostradas na Tabela 4-8. Na Tabela 4-9 são mostradas as temperaturas de entrada dos fluidos de utilidade utilizadas nas simulações do micro-organismo.

Os valores utilizados para os coeficientes globais de troca térmica entre fluido e ar ambiente das conexões e tubo de retenção foram obtidos experimentalmente no mesmo equipamento usado como exemplo no presente estudo de caso e são mostrados na Tabela 4-10. 
Tabela 4-8: Parâmetros cinéticos referentes à inativação da Coxiella burnetii (TOLEDO, 1999).

\begin{tabular}{cc}
\hline Parâmetro & Coxiella burnetii \\
\hline $\mathrm{D}_{\text {ref }}, \mathrm{S}$ & 223 \\
$\mathrm{~T}_{\text {ref }},{ }^{\circ} \mathrm{C}$ & 63 \\
$\mathrm{z},{ }^{\circ} \mathrm{C}$ & 4,34 \\
\hline
\end{tabular}

Tabela 4-9: Temperatura dos fluidos de atividade adotados na simulação.

Temperatura de Entrada

\begin{tabular}{ll}
\hline Água fria, ${ }^{\circ} \mathrm{C}$ & 10 \\
Água quente, ${ }^{\circ} \mathrm{C}$ & 75
\end{tabular}

Tabela 4-10: Coeficientes globais de troca térmica entre fluido e ar ambiente das conexões e tubo de retenção (GUTIERREZ, 2012).

\begin{tabular}{lc}
\hline \multicolumn{1}{c}{ Seção } & $\boldsymbol{U}_{\boldsymbol{t}}\left(\mathbf{W} / \mathbf{m}^{2} \cdot \mathbf{K}\right)$ \\
\hline Conexão 1 & 6,1 \\
Tubo de Retenção & 16 \\
Conexão 2 & 47 \\
\hline
\end{tabular}

O valor do coeficiente global de troca térmico na conexão 2 é muito maior do que os outros pois essa seção tubular não tem isolamento térmico, diferentemente da conexão 1 e tubo de retenção.

Foi adotada uma concentração inicial presente no produto a ser tratado de $1 \times 10^{5} \mathrm{UFC} / \mathrm{m}^{3}$. Esse valor foi escolhido, pois com ele é possível avaliar com clareza a redução do número de ciclos logarítmicos da concentração de microorganismos sem que haja comprometimento da resposta numérica fornecida pelo programa de simulação. Avaliando-se o SV pela Equação (3-36) foi possível determinar a letalidade e a eficiência de um processo térmico, independente da concentração inicial.

Para a construção do modelo do processo de pasteurização em ambiente de simulação foi utilizado o software gPROMS (Process System Enterprise, versão 3.2) e foi elaborado um sistema de equações com número de graus de liberdade nulo. 
O método de discretização utilizado na simulação foi o Método de Diferenças Finitas Centradas, do inglês Centered Finite Difference Method (CFDM), para a temperatura e concentração do micro-organismo alvo nos canais e, também, no tubo de retenção e conexões. Foram utilizados 50 pontos de discretização para os tubos e conexões e 20 pontos em cada canal das três seções do trocador, já que com esses valores foi possível fazer uma análise confiável e precisa dos resultados de simulação recolhidos. Não foi necessária a discretização de uma maior quantidade de pontos, pois isso tornaria o tempo de simulação maior e não alteraria a precisão dos resultados obtidos se comparados com uma simulação com menor número de pontos.

As variáveis discretizadas foram a temperatura e a concentração de micro-organismos ao longo dos canais do trocador, das conexões e tubo de retenção.

\subsection{Ensaios Experimentais}

A verificação da intensidade do tratamento térmico no qual o alimento foi submetido pode ser feita pela análise das distribuições de temperatura em função da distribuição do tempo de residência/tempo espacial ou experimentalmente, fazendo uso de integradores tempo-temperatura (TTI, Time-Temperature Integrator). Tal integrador é um componente termicamente sensível, intrínseco ou não ao alimento, que dá a possibilidade de quantificar o impacto do processo térmico sobre um atributo de segurança ou qualidade, sem conhecimento do histórico de temperatura. Em alguns casos em que a avaliação da eficiência do processo fosse muito custosa devido à natureza do micro-organismo, enzima ou vitamina alvo, poderia-se utilizar outros alvos que estivessem presentes no alimento para a avaliação da pasteurização, desde que fossem mais resistentes ou tivessem características cinéticas bem próximas ao alvo primário, garantindo assim que com a inativação do alvo secundário, o alvo primário também fosse inativado (MARTH; STEELE, 2001).

Após a construção e definição do modelo que descreve o processo de pasteurização, utilizou-se um indicador enzimático composto por enzima 
fosfatase alcalina de mucosa intestinal bovina (EC 3.1.3.1, Sigma-Aldrich cód. P7640) em tampão fosfato $(\mathrm{pH}=6,6)$ como indicador para validação do modelo. A atividade pôde ser determinada com sistema Reflectoquant (Merck) com kits de tiras "fosfatase alcalina em leite de 1,0 a 10,0 U/L" (AGUIAR; YAMASHITA; GUT, 2012). A atividade residual $(A R)$ foi verificada a partir da Equação (4-6):

$$
A R=\frac{A R_{f}}{A R_{0}}
$$

em que, $A R$ é a atividade enzimática média do produto em um ponto do processo e $A R_{0}$ é a atividade média da solução enzimática antes do processamento. Como a enzima fosfatase é composta por duas iso-enzimas, a atividade residual pode ser obtida pela Equação (4-7):

$$
A R=\frac{\beta \cdot A R_{1}+(1-\beta) \cdot A R_{2}}{100}
$$

em que, $A R_{1}$ é a atividade da iso-enzima 1, que é termorresistente, e $A R_{2}$ é a atividade da iso-enzima 2 , que é termolábil, ou seja, tem a tendência a decompor-se sob a inflência da temperatura. Os parâmetros cinéticos das isoenzimas são dados por $z_{1}=5,58{ }^{\circ} \mathrm{C}$ e $z_{2}=11,38{ }^{\circ} \mathrm{C}$, e o parâmetro $\beta=0,62$, assim como os apresentados na Tabela 4-11 (AGUIAR; YAMASHITA; GUT, 2012).

Tabela 4-11: Parâmetros cinéticos do indicador enzimático nas temperaturas processadas (AGUIAR; YAMASHITA; GUT, 2012).

\begin{tabular}{lllll}
\hline & & & (AGUIAR; YAMASHITA; GUT, 2012). & \\
\hline$D_{1}(\mathrm{~s})$ & 4542 & $\mathbf{7 5}{ }^{\circ} \mathbf{C}$ & $\mathbf{8 0}^{\circ} \mathbf{C}$ & $\mathbf{8 5}^{\circ} \mathbf{C}$ \\
$D_{2}(\mathrm{~s})$ & 42 & 578 & 73 & 9,0 \\
\hline
\end{tabular}

Foram então realizados experimentos de processamento contínuo, nas temperaturas de $70{ }^{\circ} \mathrm{C}, 75^{\circ} \mathrm{C}, 80^{\circ} \mathrm{C}$ e $85^{\circ} \mathrm{C}$, com o indicador ALP no 
pasteurizador laboratorial Armfield operando nas condições nominais, com vazão do produto de $20 \mathrm{~L} / \mathrm{h}$ e fluidos de utilidade a 1,0 L/min.

Dado início no processo de pasteurização, esperou-se até que fosse atingido o estado estacionário, a partir desse instante a coleta dos dados de temperatura fornecidos pelos termopares teve início e retiraram-se cinco amostras do produto processado na saída do aquecimento e na saída do resfriamento para cada uma das quatro temperaturas de processamento (pontos T3 e T8 na Figura 4-3). Também foram feitas duas medidas das atividades do produto na temperatura ambiente em dois momentos distintos no dia da realização do experimento. A coleta das amostras foi feita na saída da seção de resfriamento e da seção de aquecimento de maneira rápida e, em seguida, armazenadas em banho de gelo para impedir a continuidade da inativação das enzimas.

Para a medida da atividade residual do produto processado seguiu-se 0 método descrito pelo fabricante do kit utilizado na preparação da amostra, Reflectoquant (Merck). Esse método baseia-se na utilização de três soluções não especificadas pelo fabricante (ALP-1, ALP-2 e ALP-3) para que, em presença da enzima fosfatase alcalina, um substrato específico seja transformado em um corante azul e posteriormente sua concentração determinada reflectometricamente. Primeiramente a solução ALP-2 foi misturada no fraco contendo ALP-1, agitou-se o recipiente para deixar a solução pronta para uso. Foram distribuídas 15 gotas da ALP-1 em cubetas e essas levadas a um banho térmico a $37^{\circ} \mathrm{C}$. Foram retirados $5 \mathrm{~mL}$ de amostra do produto processado que estava em banho com gelo e misturou-se 10 gotas da ALP-3 em um béquer. Tiras de papel do kit com faixas de indicador lidas pelo reflectômetro foram mergulhadas por 2 segundos no béquer contendo o produto processado e a ALP-3. Em seguida, as tiras foram armazenadas nas cubetas em banho a $37{ }^{\circ} \mathrm{C}$ durante 20 minutos. Após esse período foram retiradas e a atividade residual medida a partir da tira de papel em um reflectômetro. 


\subsection{Validação do Modelo}

Para verificar a qualidade da modelagem, foram realizadas simulações com o modelo desenvolvido nas mesmas condições de operação do experimento e os resultados comparados com os dados coletados experimentalmente.

Para que o modelo pudesse ser simulado, os principais parâmetros especificados foram: as vazões e as temperaturas de entrada dos fluidos de processo e utilidade (água de aquecimento e resfriamento), a concentração inicial da espécie a ser pasteurizada, a temperatura de referência e tempo de redução decimal do micro-organismo ou enzima, o parâmetro da cinética de inativação térmica e as dimensões e características das seções e conexões do pasteurizador.

Foram feitas comparações para a distribuição de temperatura e distribuição de letalidade, sendo a última avaliada tanto em históricos utilizando o tempo espacial e tempo médio de residência. 


\section{$5 \quad$ RESULTADOS E DISCUSSÃO}

\subsection{Exemplos de Simulação}

Primeiramente, os resultados das simulações usando tempo espacial e tempo médio de residência na pasteurização visando a inativação da Coxiella burnetii, a partir da modelagem desenvolvida, são mostrados. Esses resultados englobam a distribuição dos valores de temperatura do produto e do histórico de letalidade ao longo dos canais do trocador e do tubo de retenção e conexões, sendo possível observar com detalhes os seus comportamentos em uma determinada seção de escolha do PHE, de acordo com as regiões mostradas na Figura 5-1 e Figura 5-2.

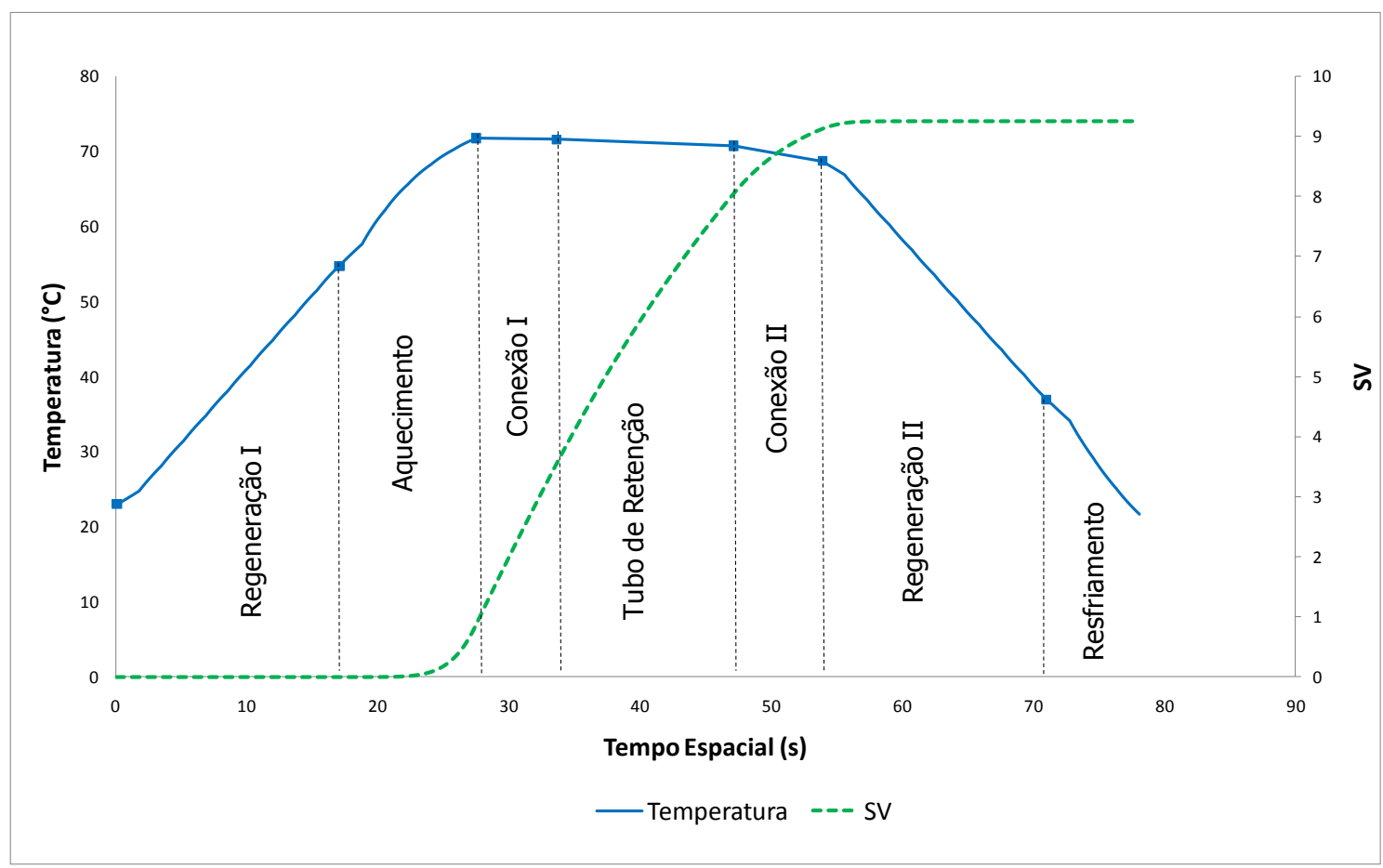

Figura 5-1: Distribuição de temperatura e valor de esterilização simulados para Coxiella burnetii usando tempo espacial. 


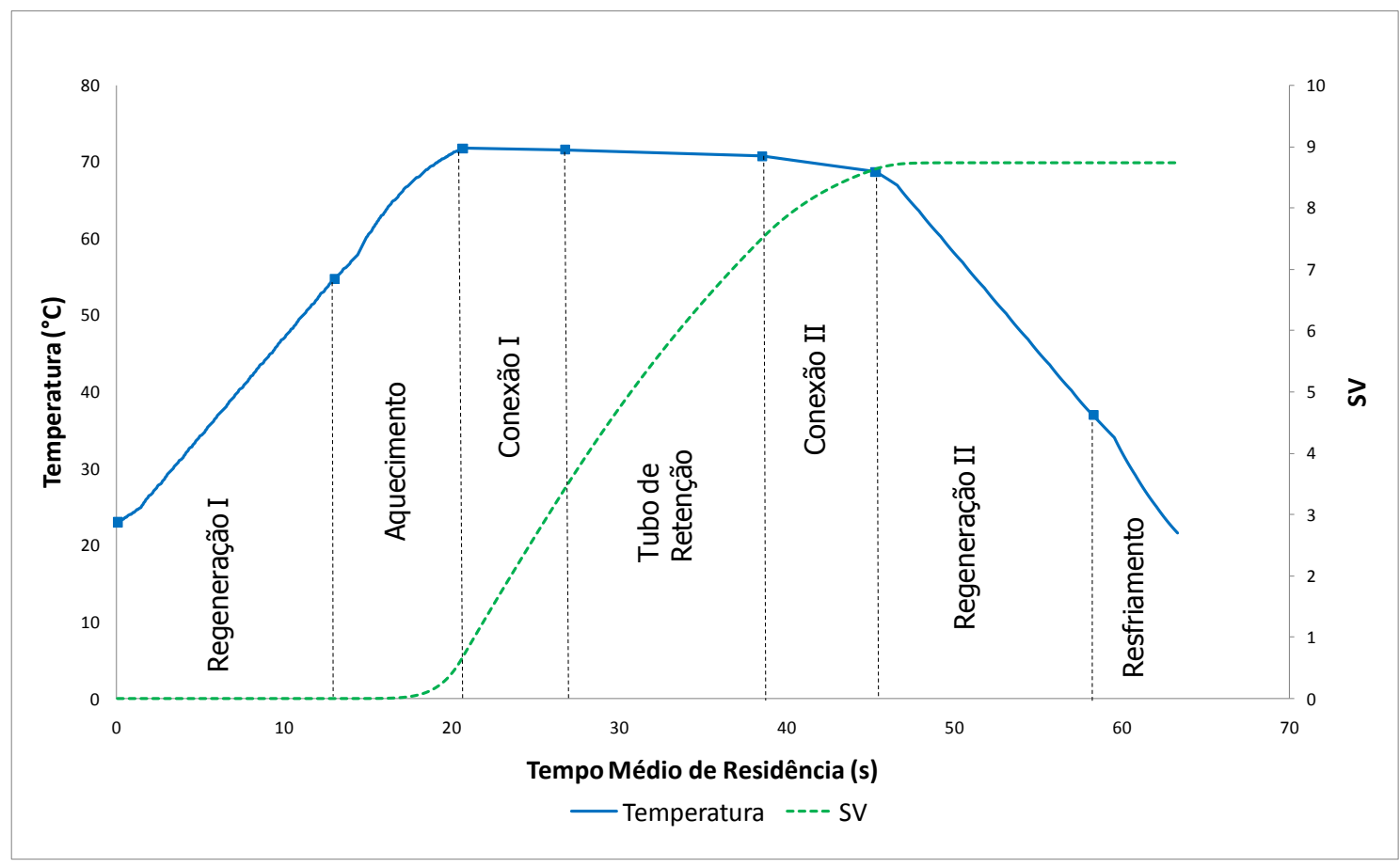

Figura 5-2: Distribuição de temperatura e valor de esterilização simulados para Coxiella burnetii usando tempo médio de residência.

De acordo com Fellows (1999), tanto o aquecimento quanto o resfriamento podem contribuir para o processo de pasteurização e quando essas etapas ocorrem rapidamente, a parcela mais significante da inativação do micro-organismo ou enzima alvo ocorre no tubo de retenção. No entanto, mesmo nesse último caso, são necessários procedimentos para avaliar cada um desses períodos individualmente. No caso ideal, o aquecimento e o resfriamento ocorrem instantaneamente e a destruição se passa exclusivamente na retenção em temperatura constante. Tal comportamento ideal não foi verificado nos resultados das simulações presentes nesse trabalho, já que na Figura 5-1 e Figura 5-2, que mostram a temperatura do produto e o decaimento decimal da concentração ao longo do trocador de calor, foi possível observar que o aquecimento e o resfriamento não são instantâneos (ocorrem ao longo de suas seções) e há a inativação, ainda que em pequena escala, do micro-organismo alvo nessas seções, verificada pela mudança nos valores de SV. Foi possível verificar também que a contribuição das conexões 1 e 2 é significativa na inativação.

O comportamento observado nas simulações das Figura 5-1 e 5-2 é o desejado, já que se espera que no tubo de retenção ocorra a destruição mais 
eficiente da espécie alvo. Nesse estudo de caso, o maior aumento da ordem de grandeza do decaimento logarítmico ocorreu na retenção, com valor próximo a quatro.

Na Tabela 5-1 são mostrados os valores de esterilização em cada seção do pasteurizador para a simulação usando o tempo médio de residência e o tempo espacial. Levando em consideração o uso do tempo espacial, espera-se que o valor de esterilização alcançado seja maior, ou seja, que a inativação atingida seja maior do que a verificada com o tempo médio de residência, pois o produto passa mais tempo no pasteurizador e, portanto o tratamento térmico é mais longo e a destruição do micro-organismo é mais intensa.

\begin{tabular}{|c|c|c|}
\hline & \multicolumn{2}{|c|}{ SV acumulado } \\
\hline & $\begin{array}{l}\text { Tempo médio de } \\
\text { residência }\end{array}$ & $\begin{array}{c}\text { Tempo } \\
\text { espacial }\end{array}$ \\
\hline Regeneração 1 & $4,3 \cdot 10^{-5}$ & $4,6.10^{-5}$ \\
\hline Aquecimento & 0,67 & 0,88 \\
\hline Conexão 1 & 3,42 & 3,55 \\
\hline Tubo de Retenção & 7,49 & 8,05 \\
\hline Conexão 2 & 8,63 & 9,13 \\
\hline Regeneração 2 & 8,73 & 9,26 \\
\hline Resfriamento & 8,73 & 9,26 \\
\hline
\end{tabular}

Kechichian et al. (2012) e Jung e Fryer (1999) desenvolveram e testaram modelos matemáticos para o processamento térmico contínuo de alimentos líquidos em trocador de calor bitubular. As curvas de letalidade dos atributos de segurança obtidas apresentaram comportamentos e tendências semelhantes às curvas de decaimento decimal da concentração do microorganismo desenvolvidas no presente trabalho, em que também ocorre significante contribuição da seção de aquecimento no processamento térmico. Dessa maneira, é possível observar que para não haver superdimensionamento do equipamento e sobreprocessamento do produto, 
todas as partes que compõem o processo devem ser consideradas no cálculo de letalidade.

$\mathrm{Na}$ simulação do modelo desenvolvido, observou-se a queda de temperatura do produto a ser pasteurizado dentro do tubo de retenção. Essa queda teve um valor próximo de $1^{\circ} \mathrm{C}$. A verificação desse valor é importante para a realização de um processo mais rigoroso em relação à segurança alimentar e ao consumo energético, pois assim sabe-se a temperatura mínima em que a água de aquecimento deve entrar no processo para garantir a pasteurização desejada.

É possível observar na distribuição do valor de esterilização que as conexões tubulares contribuem de maneira intensa na destruição da bactéria. Portanto, torna-se interessante fazer um estudo da distribuição do tempo de residência nessas seções e acoplar seu resultado à modelagem que leva em conta o tempo de residência.

\subsection{Resultados Experimentais}

A partir do procedimento experimental em que uma solução tampão contendo enzima fosfatase alcalina foi processada em quatro temperaturas diferentes, mediu-se a atividade enzimática do produto pasteurizado em amostras retiradas na saída da seção de aquecimento e também de resfriamento. Os valores das atividades residuais das amostras na saída do aquecimento (T3) e saída do resfriamento (T8) para as quatro temperaturas de processamento $\left(70,75,80\right.$ e $\left.85^{\circ} \mathrm{C}\right)$ são mostrados na Tabela $5-2$, sendo LOW obtido quando o aparelho utilizado para medição da atividade não retornava resultado, pois o valor de concentração era muito baixo. Também foram obtidos os valores de temperatura do produto na saída dos trocadores de calor e das seções tubulares seguindo a nomenclatura da Figura 4-3. As médias são mostradas na Tabela 5-3, sendo que o erro refere-se à aquisição dos dados no intervalo da coleta, o erro referente ao termopar é de $0,5^{\circ} \mathrm{C}$. Os valores das atividades enzimáticas médias da enzima não processada foram 6,1 U/L (com 
desvio de 0,4$)$ no processamento a $70^{\circ} \mathrm{C}$ e $75^{\circ} \mathrm{C}$ e $6,4 \mathrm{U} / \mathrm{L}$ (com desvio de 0,6 ) nos demais.

Foi realizado o balanço de energia com os dados experimentais no processamento em todas as temperaturas testadas para verificação da hipótese de conservação de energia nas três seções de troca térmica, em que o calor cedido pelo fluido quente e recebido pelo fluido frio são iguais $\left(Q_{h o t}=\right.$

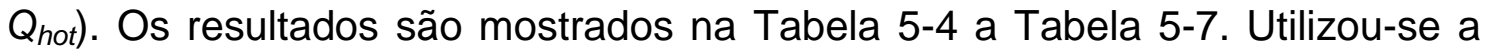
Equação (5-1) para determinar o erro, ou seja, determinar a parcela do calor que não foi absorvido pelo fluido frio e, provavelmente, cedido ao ambiente.

$$
\text { Erro }=\frac{Q_{\text {hot }}-Q_{\text {cold }}}{Q_{\text {hot }}}
$$

Como pode ser visto na Tabela 5-4 a Tabela 5-7, percebe-se que o aquecimento e o resfriamento foram as seções em que o erro ficou mais significante. Era esperado que no aquecimento a diferença fosse maior, devido a alta temperatura e possivelmente uma perda mais intensa de calor para 0 ambiente. Já no resfriamento esperava-se que o erro fosse menor, pois o fluido frio (água de resfriamento) receberia calor do ambiente, já que a temperatura desse está maior do que a da água. O valor do erro no balanço no resfriamento pode ser creditado ao problema de registro de temperatura do termopar na entrada ou saída da seção de resfriamento ou dos termopares responsáveis pelo registro de temperatura da água de resfriamento.

Tabela 5-2: Dados experimentais de atividade enzimática coletados (U/L)

\begin{tabular}{|c|c|c|c|c|c|c|c|c|}
\hline & 1 & 2 & 3 & 4 & 5 & Média & Desvio & AR \\
\hline $\mathrm{T} 8$ a $70^{\circ} \mathrm{C}$ & 5,1 & 5,6 & 5,6 & 4,9 & 5,6 & 5,4 & 0,3 & $88 \%$ \\
\hline T3 a $70^{\circ} \mathrm{C}$ & 6,2 & 6,4 & 6,5 & 5,3 & 5,7 & 6,0 & 0,5 & $99 \%$ \\
\hline T8 a $75^{\circ} \mathrm{C}$ & 4,0 & 3,4 & 3,8 & 4,0 & 4,1 & 3,9 & 0,2 & $63 \%$ \\
\hline T3 a $75^{\circ} \mathrm{C}$ & 5,6 & 6,4 & 4,5 & 5,5 & 5,3 & 5,5 & 0,6 & $90 \%$ \\
\hline $\mathrm{T} 8$ a $80^{\circ} \mathrm{C}$ & 2,0 & 2,2 & 2,2 & 2,1 & 2,6 & 2,2 & 0,2 & $35 \%$ \\
\hline $\mathrm{T} 3$ a $80^{\circ} \mathrm{C}$ & 3,4 & 3,5 & 3,6 & 3,5 & 4,5 & 3,7 & 0,4 & $58 \%$ \\
\hline $\mathrm{T} 8$ a $85^{\circ} \mathrm{C}$ & 0,9 & 1,0 & LOW & 1,0 & 1,1 & 1,0 & 0,1 & $16 \%$ \\
\hline $\mathrm{T} 3$ a $85^{\circ} \mathrm{C}$ & 1,8 & 1,8 & 1,5 & 2,0 & 2,3 & 1,9 & 0,3 & $29 \%$ \\
\hline
\end{tabular}


Tabela 5-3: Dados experimentais de temperatura coletados.

\begin{tabular}{lcccc}
\hline Condições & $\mathbf{7 0}^{\circ} \mathbf{C}$ & $\mathbf{7 5}{ }^{\circ} \mathbf{C}$ & $\mathbf{8 0}^{\circ} \mathbf{C}$ & $\mathbf{8 5}^{\circ} \mathbf{C}$ \\
\hline Regeneração 1 & $55,32 \pm 0,05$ & $58,29 \pm 0,05$ & $61,94 \pm 0,08$ & $65,48 \pm 0,10$ \\
Aquecimento & $70,74 \pm 0,04$ & $76,02 \pm 0,07$ & $80,96 \pm 0,05$ & $86,45 \pm 0,07$ \\
Conexão 1 & $70,57 \pm 0,03$ & $75,82 \pm 0,05$ & $80,88 \pm 0,03$ & $86,05 \pm 0,08$ \\
Tubo de retenção & $70,19 \pm 0,05$ & $75,62 \pm 0,04$ & $80,49 \pm 0,05$ & $85,70 \pm 0,07$ \\
Conexão 2 & $66,87 \pm 0,04$ & $71,87 \pm 0,03$ & $76,49 \pm 0,04$ & $81,17 \pm 0,06$ \\
Regeneração 2 & $33,71 \pm 0,05$ & $35,07 \pm 0,08$ & $35,70 \pm 0,08$ & $36,71 \pm 0,06$ \\
Resfriamento & $15,69 \pm 0,04$ & $17,18 \pm 0,06$ & $19,18 \pm 0,12$ & $20,35 \pm 0,14$ \\
\hline
\end{tabular}

Tabela 5-4: Balanço de energia com valores experimentais nas três seções do pasteurizador no processamento a $70^{\circ} \mathrm{C}$

\begin{tabular}{cccc}
\multicolumn{4}{c}{ processamento a $70^{\circ} \mathrm{C}}$. \\
\hline Seção & & [W] & Erro \\
\hline Regeneração & $\mathrm{Q}_{\text {hot }}$ & 832 & \multirow{2}{*}{$1 \%$} \\
& $\mathrm{Q}_{\text {cold }}$ & 821 & \\
Aquecimento & $\mathrm{Q}_{\text {hot }}$ & 394 & \multirow{2}{*}{$2 \%$} \\
& $\mathrm{Q}_{\text {cold }}$ & 387 & \\
Resfriamento & $\mathrm{Q}_{\text {hot }}$ & 488 & \multirow{2}{*}{$7 \%$} \\
& $\mathrm{Q}_{\text {cold }}$ & 453 & \\
\hline
\end{tabular}

Tabela 5-5: Balanço de energia com valores experimentais nas três seções do pasteurizador no processamento a $75^{\circ} \mathrm{C}$.

\begin{tabular}{|c|c|c|c|}
\hline Seção & & [W] & Erro \\
\hline \multirow[t]{2}{*}{ Regeneração } & $Q_{\text {hot }}$ & 924 & \multirow{2}{*}{$2 \%$} \\
\hline & $Q_{\text {cold }}$ & 907 & \\
\hline \multirow[t]{2}{*}{ Aquecimento } & $Q_{\text {hot }}$ & 503 & \multirow{2}{*}{$12 \%$} \\
\hline & $Q_{\text {cold }}$ & 445 & \\
\hline \multirow[t]{2}{*}{ Resfriamento } & $Q_{\text {hot }}$ & 498 & \multirow{2}{*}{$10 \%$} \\
\hline & $Q_{\text {cold }}$ & 449 & \\
\hline
\end{tabular}

Tabela 5-6: Balanço de energia com valores experimentais nas três seções do pasteurizador no

\begin{tabular}{cccc}
\multicolumn{4}{c}{ processamento a $80^{\circ} \mathrm{C}}$. \\
\hline Seção & & [W] & Erro \\
\hline Regeneração & $Q_{\text {hot }}$ & 1024 & $2 \%$ \\
& $Q_{\text {cold }}$ & 1001 & \\
Aquecimento & $Q_{\text {hot }}$ & 532 & \multirow{2}{*}{$10 \%$} \\
& $Q_{\text {cold }}$ & 478 & \\
Resfriamento & $Q_{\text {hot }}$ & 484 & $14 \%$ \\
& $Q_{\text {cold }}$ & 415 & \\
\hline
\end{tabular}


Tabela 5-7: Balanço de energia com valores experimentais nas três seções do pasteurizador no

\begin{tabular}{|c|c|c|c|}
\hline Seção & & [W] & Erro \\
\hline \multirow{2}{*}{ Regeneração } & $\mathrm{Q}_{\text {hot }}$ & 1117 & \multirow{2}{*}{$2 \%$} \\
\hline & $Q_{\text {cold }}$ & 1091 & \\
\hline \multirow[t]{2}{*}{ Aquecimento } & $\mathrm{Q}_{\text {hot }}$ & 573 & \multirow{2}{*}{$8 \%$} \\
\hline & $Q_{\text {cold }}$ & 528 & \\
\hline \multirow[t]{2}{*}{ Resfriamento } & $Q_{\text {hot }}$ & 477 & \multirow{2}{*}{$14 \%$} \\
\hline & $Q_{\text {cold }}$ & 411 & \\
\hline
\end{tabular}

\subsection{Validação do Modelo}

$\mathrm{Na}$ validação do modelo utilizou-se a hipótese de que as propriedades do indicador enzimático fossem iguais as da água. Isso é possível, pois a concentração do indicador enzimático era muito baixa.

Para avaliação das temperaturas determinadas pelo modelo desenvolvido, foram verificadas as distribuições de temperaturas experimentais nos processamentos da enzima alvo a $70{ }^{\circ} \mathrm{C}, 75^{\circ} \mathrm{C}, 80^{\circ} \mathrm{C}$ e $85^{\circ} \mathrm{C}$. A comparação entre os resultados experimentais e simulados são mostrados na Figura 5-3 a Figura 5-6.

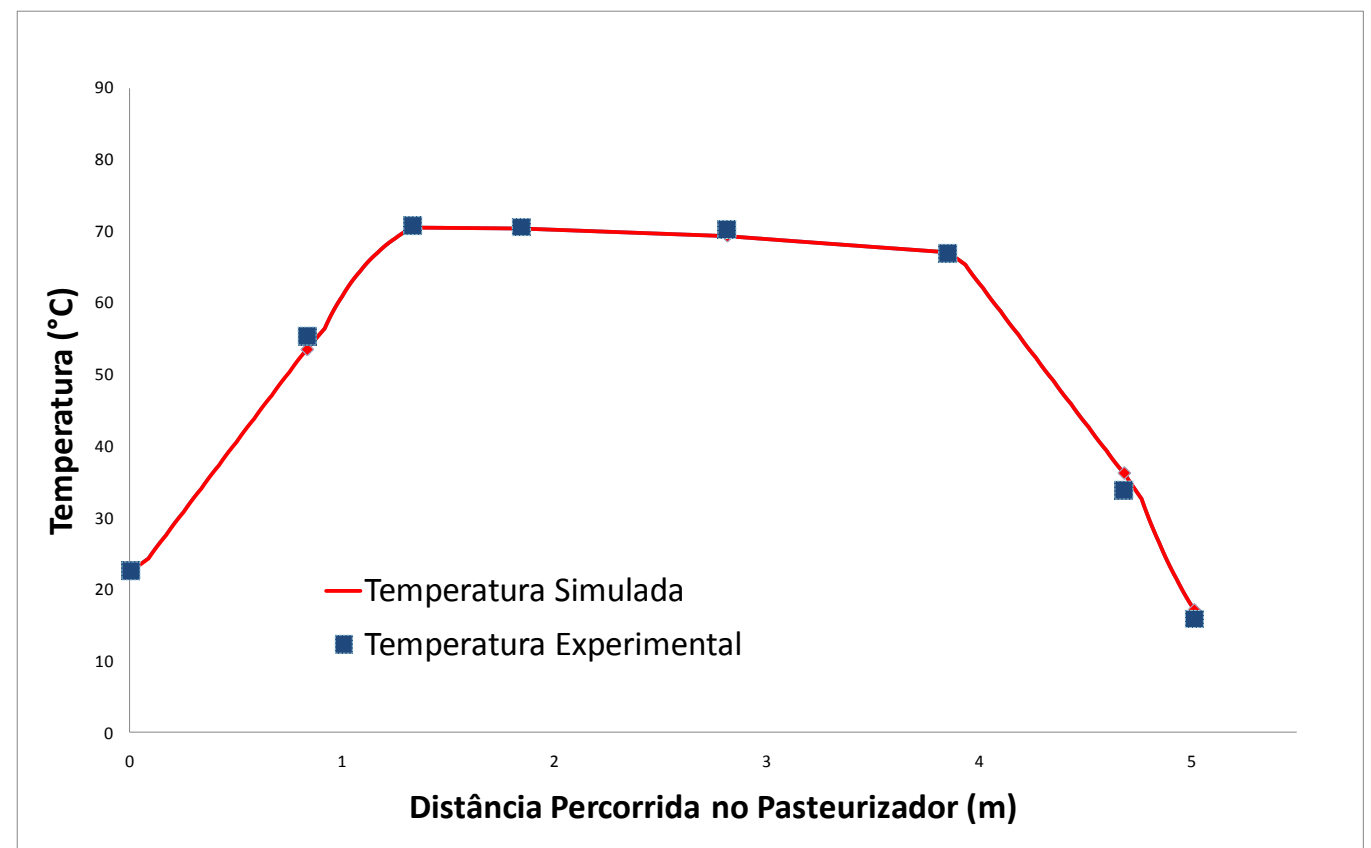

Figura 5-3: Distribuição de temperatura experimental e simulada para processamento do indicador enzimático a $70^{\circ} \mathrm{C}$. 


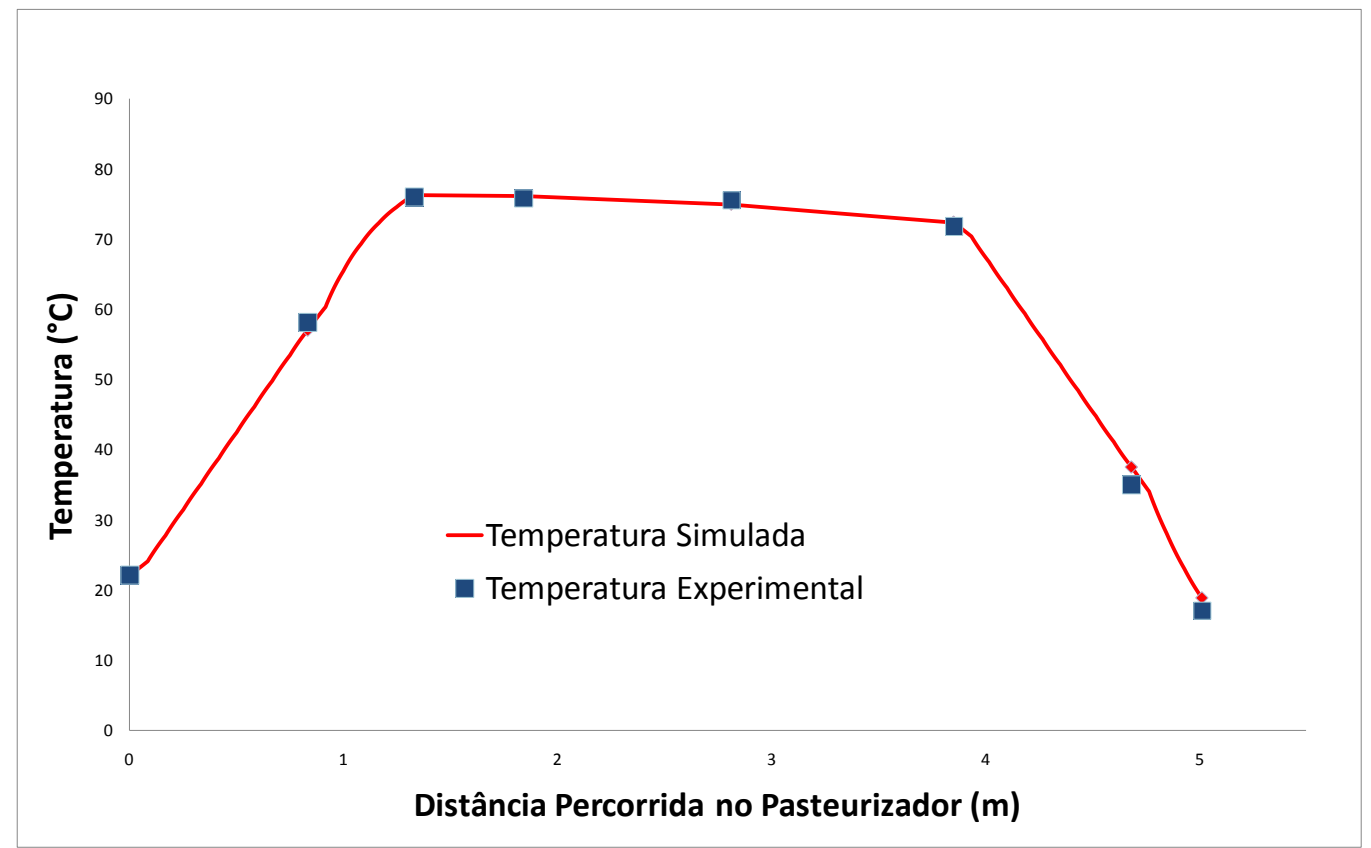

Figura 5-4: Distribuição de temperatura experimental e simulada para processamento do indicador enzimático a $75^{\circ} \mathrm{C}$.

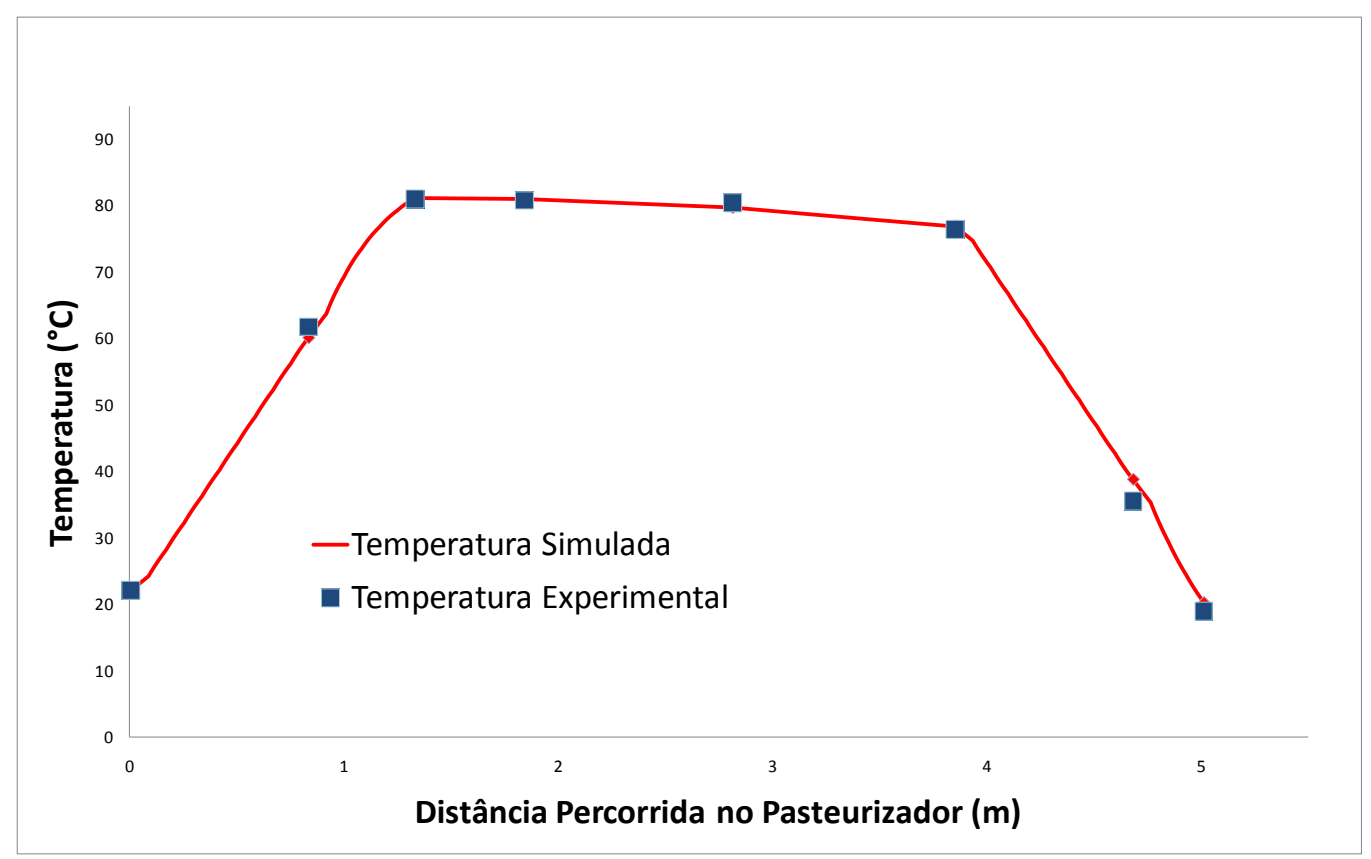

Figura 5-5: Distribuição de temperatura experimental e simulada para processamento do indicador enzimático a $80^{\circ} \mathrm{C}$. 


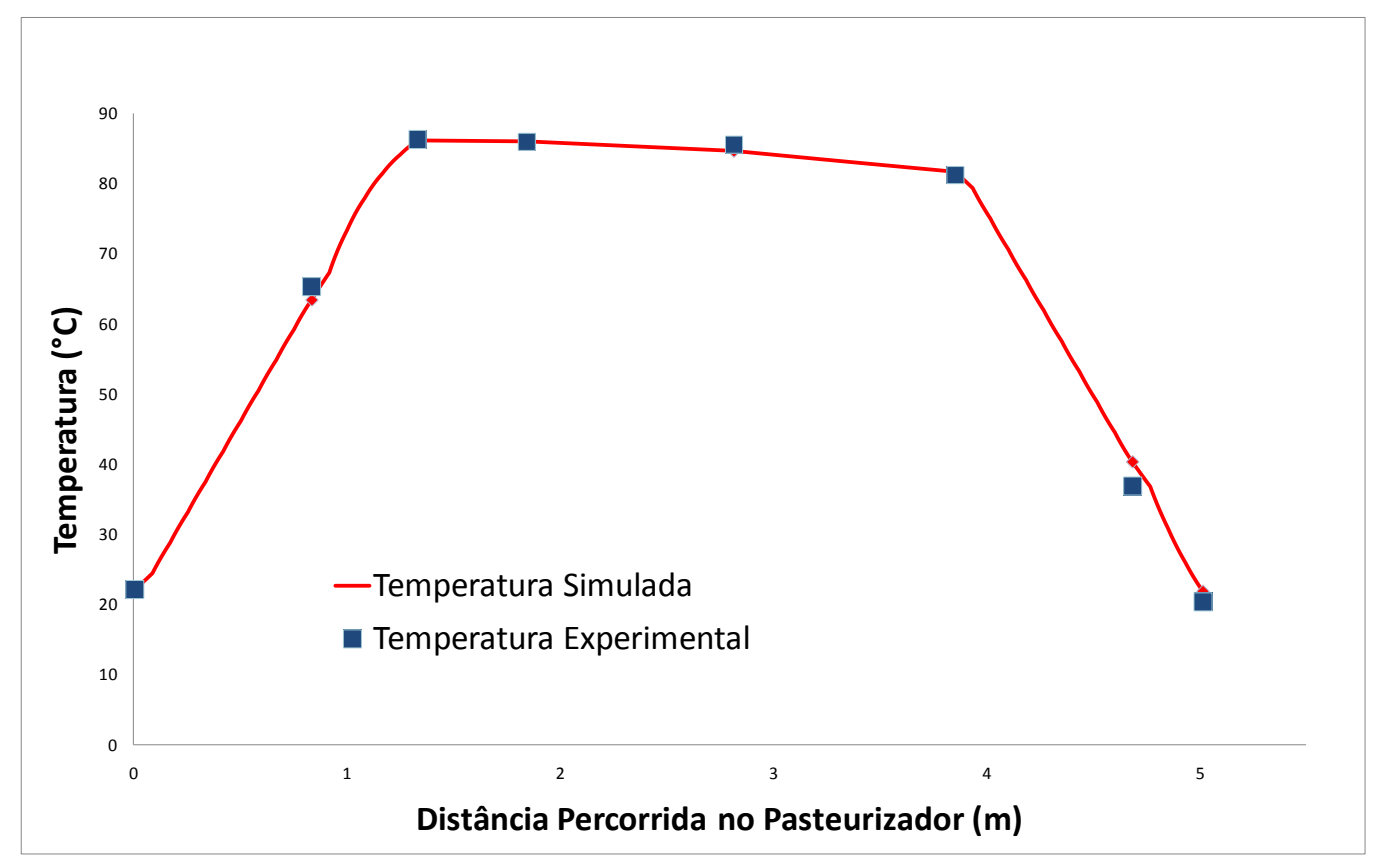

Figura 5-6: Distribuição de temperatura experimental e simulada para processamento do indicador enzimático a $85^{\circ} \mathrm{C}$.

Comparando as temperaturas do modelo com as experimentais, observa-se que os valores apresentam pouca diferença entre si nas quatro condições de processamento, mostrando que o modelo descreve bem a troca térmica da pasteurização nos pontos estudados. Em todos os casos foi possível observar que na saída da segunda seção de regeneração ocorreu maior diferença entre as temperaturas simuladas e experimentais.

As curvas das Figura 5-7 a Figura 5-10 mostram a atividade residual simulada da enzima ao longo dos processamentos contínuos, nas temperaturas nominais de pasteurização a $70^{\circ} \mathrm{C}, 75^{\circ} \mathrm{C}, 80^{\circ} \mathrm{C}$ e $85^{\circ} \mathrm{C}$. 


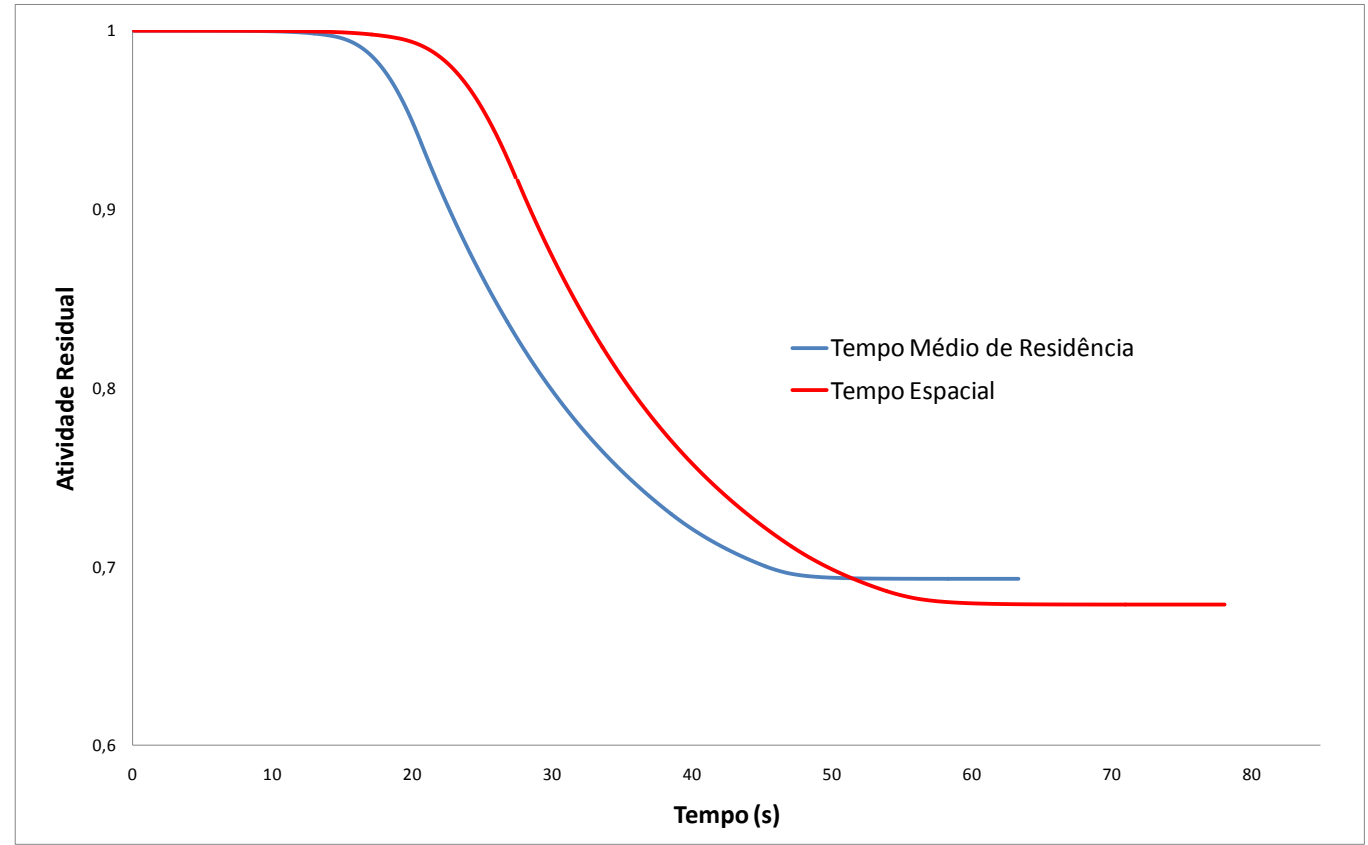

Figura 5-7: Histórico da atividade residual do indicador enzimático ao longo do pasteurizador para processamento a $70^{\circ} \mathrm{C}$.

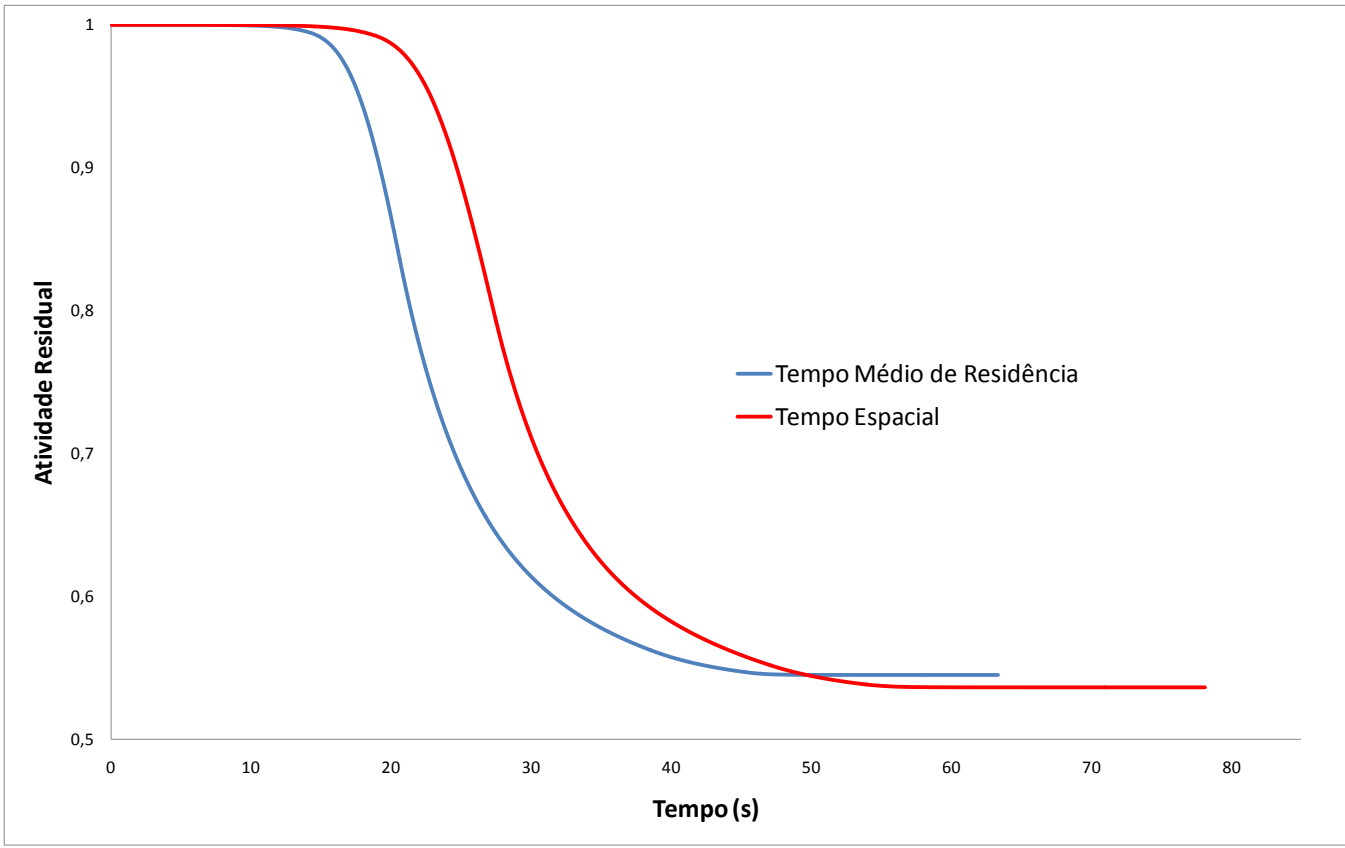

Figura 5-8: Histórico da atividade residual do indicador enzimático ao longo do pasteurizador para processamento a $75^{\circ} \mathrm{C}$. 


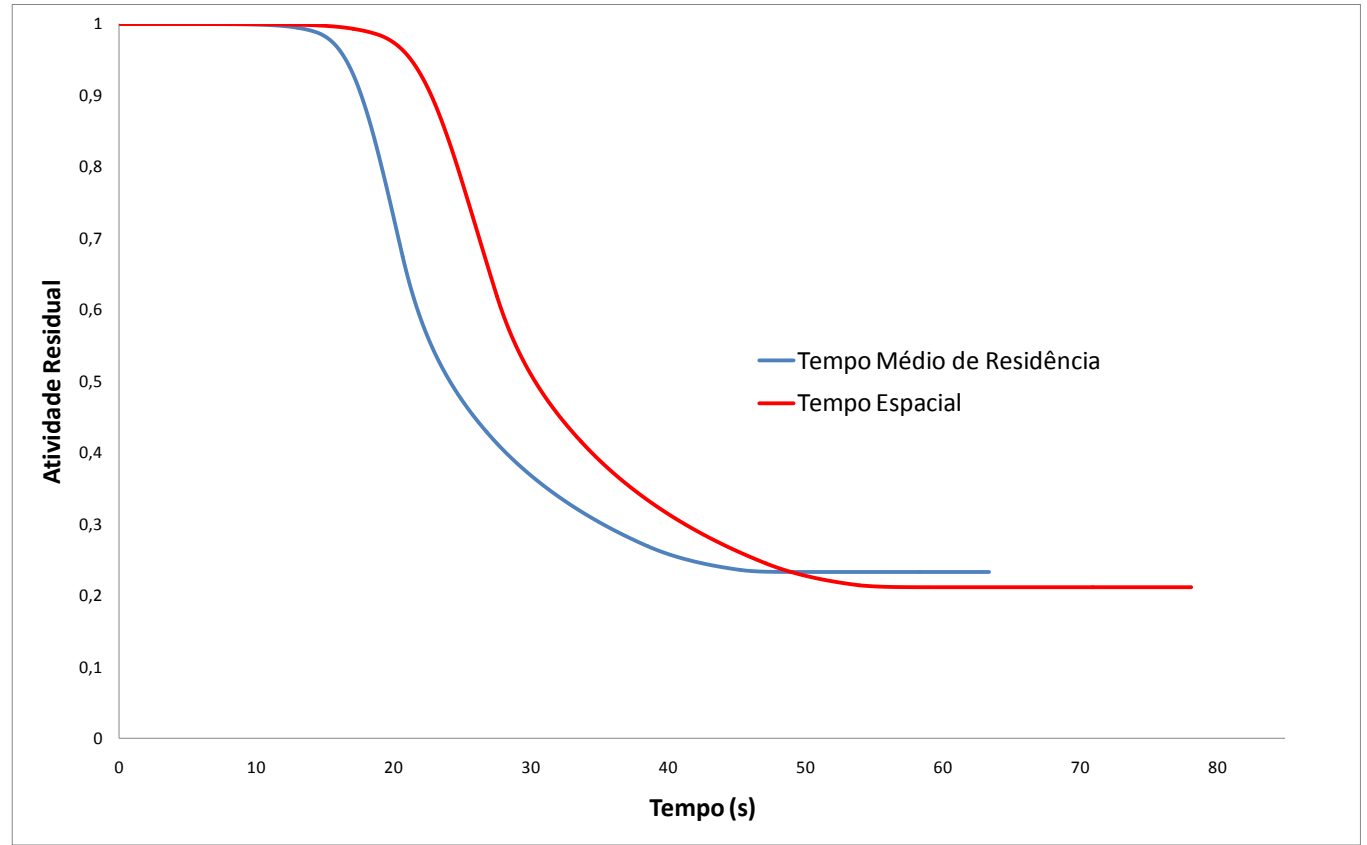

Figura 5-9: Histórico da atividade residual do indicador enzimático ao longo do pasteurizador para processamento a $80^{\circ} \mathrm{C}$.

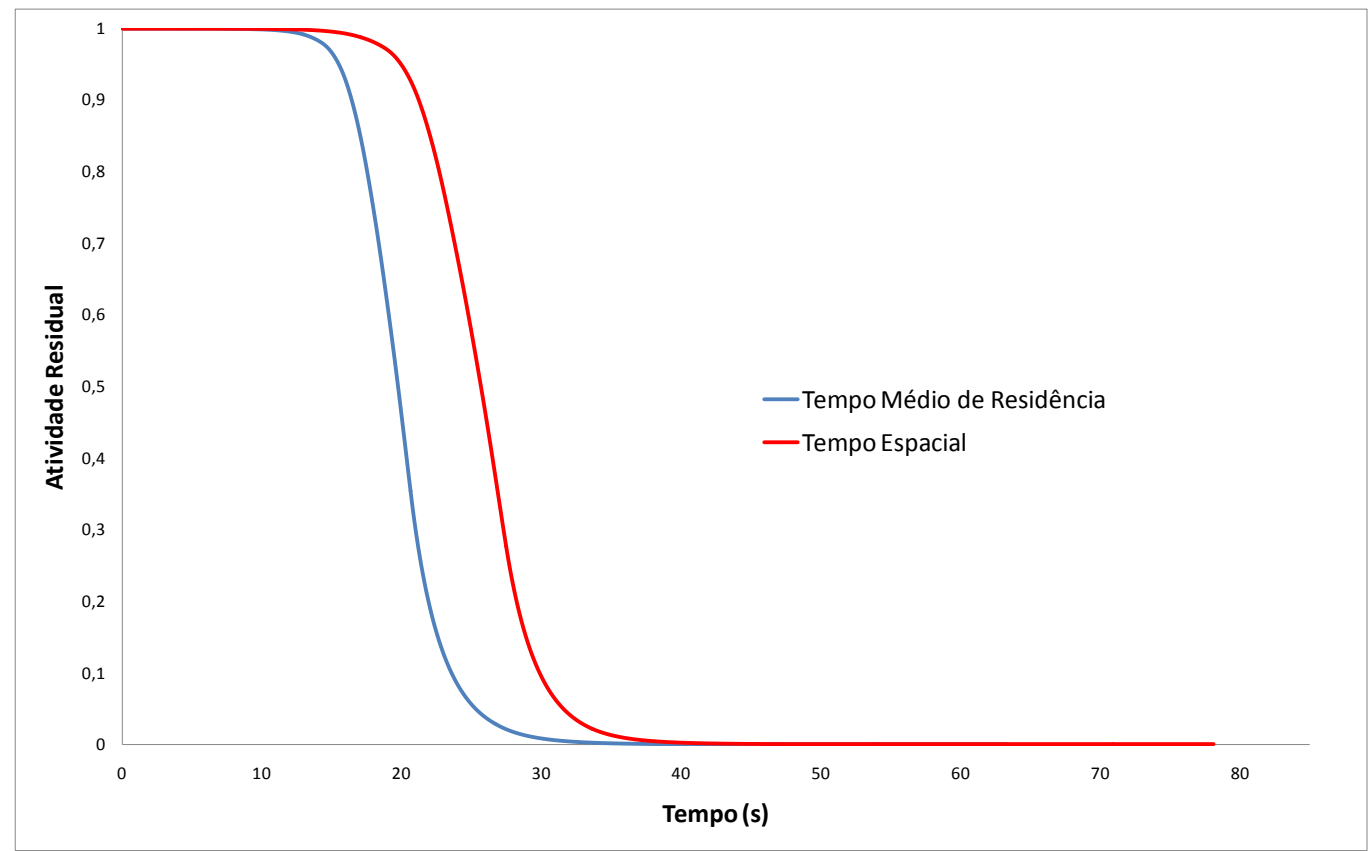

Figura 5-10: Histórico da atividade residual do indicador enzimático ao longo do pasteurizador para processamento a $85^{\circ} \mathrm{C}$. 
Tabela 5-8: Atividade residual do indicador enzimático em cada trecho do pasteurizador nas simulações de tempo médio de residência e tempo espacial.

\begin{tabular}{lcccccccc}
\hline & \multicolumn{1}{c}{$\mathbf{7 0}{ }^{\circ} \mathbf{C}$} & \multicolumn{2}{c}{$\mathbf{7 5}{ }^{\circ} \mathbf{C}$} & \multicolumn{2}{c}{$\mathbf{8 0}{ }^{\circ} \mathbf{C}$} & \multicolumn{2}{c}{$\mathbf{8 5}{ }^{\circ} \mathbf{C}$} \\
\hline & $\boldsymbol{t}_{\mathbf{m}}$ & $\mathbf{\tau}$ & $\boldsymbol{t}_{\mathbf{m}}$ & $\boldsymbol{\tau}$ & $\boldsymbol{t}_{\mathbf{m}}$ & $\boldsymbol{\tau}$ & $\boldsymbol{t}_{\mathbf{m}}$ & $\boldsymbol{\tau}$ \\
Regeneração 1 & 0,998 & 0,998 & 0,997 & 0,996 & 0,995 & 0,993 & 0,991 & 0,988 \\
Aquecimento & 0,937 & 0,916 & 0,835 & 0,792 & 0,674 & 0,618 & 0,353 & 0,276 \\
Conexão 1 & 0,837 & 0,823 & 0,656 & 0,641 & 0,428 & 0,415 & 0,028 & 0,022 \\
Tubo de Retenção & 0,729 & 0,711 & 0,562 & 0,552 & 0,269 & 0,244 & 0,000 & 0,000 \\
Conexão 2 & 0,699 & 0,686 & 0,547 & 0,538 & 0,236 & 0,214 & 0,000 & 0,000 \\
Regeneração 2 & 0,693 & 0,679 & 0,545 & 0,536 & 0,232 & 0,211 & 0,000 & 0,000 \\
Resfriamento & 0,693 & 0,678 & 0,545 & 0,536 & 0,232 & 0,211 & 0,000 & 0,000 \\
\hline
\end{tabular}

Em todos os casos foram comparados os comportamentos da inativação entre um processo que leva em conta o tempo médio de residência e o que leva em conta o tempo espacial. É esperado que a atividade residual seja menor para o processo definido com o tempo espacial, pois o produto passa mais tempo sendo processado, atingindo uma letalidade maior. Esse comportamento pode ser observado na Tabela 5-8, que explicita as atividades residuais simuladas ao longo do processo. No entanto, observa-se uma proximidade entre os valores que pode ser explicada pelo fato do indicador utilizado para a validação da modelagem apresentar uma fração de iso-enzima termorresistente e uma fração termolábil e, dessa forma, o processo HTST, tanto no modelo com tempo espacial quanto no modelo com tempo médio de residência, não seria suficiente para inativar a parcela termorresistente, necessitando de tempo maior de tratamento para que isso ocorresse.

Ao analisar os resultados experimentais e as simulações dos modelos não foi possível determinar qual modelo se aproxima mais do processo real, no que se refere à distribuição da concentração do micro-organismo, enzima ou vitamina alvo. Porém, pode-se afirmar que, com base na proximidade dos resultados experimentais e simulados de distribuição de temperatura, a modelagem desenvolvida representa de forma satisfatória o processo de pasteurização em trocadores de calor a placas.

A avaliação da atividade residual experimental com a simulada é feita a partir dos valores medidos das amostras retiradas na saída das seções de 
aquecimento e resfriamento em processamentos contínuos a $70^{\circ} \mathrm{C}, 75^{\circ} \mathrm{C}, 80$ ${ }^{\circ} \mathrm{C}$ e $85^{\circ} \mathrm{C}$ dos ensaios experimentais e das atividades obtidas nas simulações nas mesmas condições, tanto para o tempo espacial quanto para o tempo médio de residência. Na Figura 5-11, estão mostradas as atividades residual da enzima na saída do aquecimento e, na Figura 5-12, as curvas referentes à saída da seção de resfriamento.

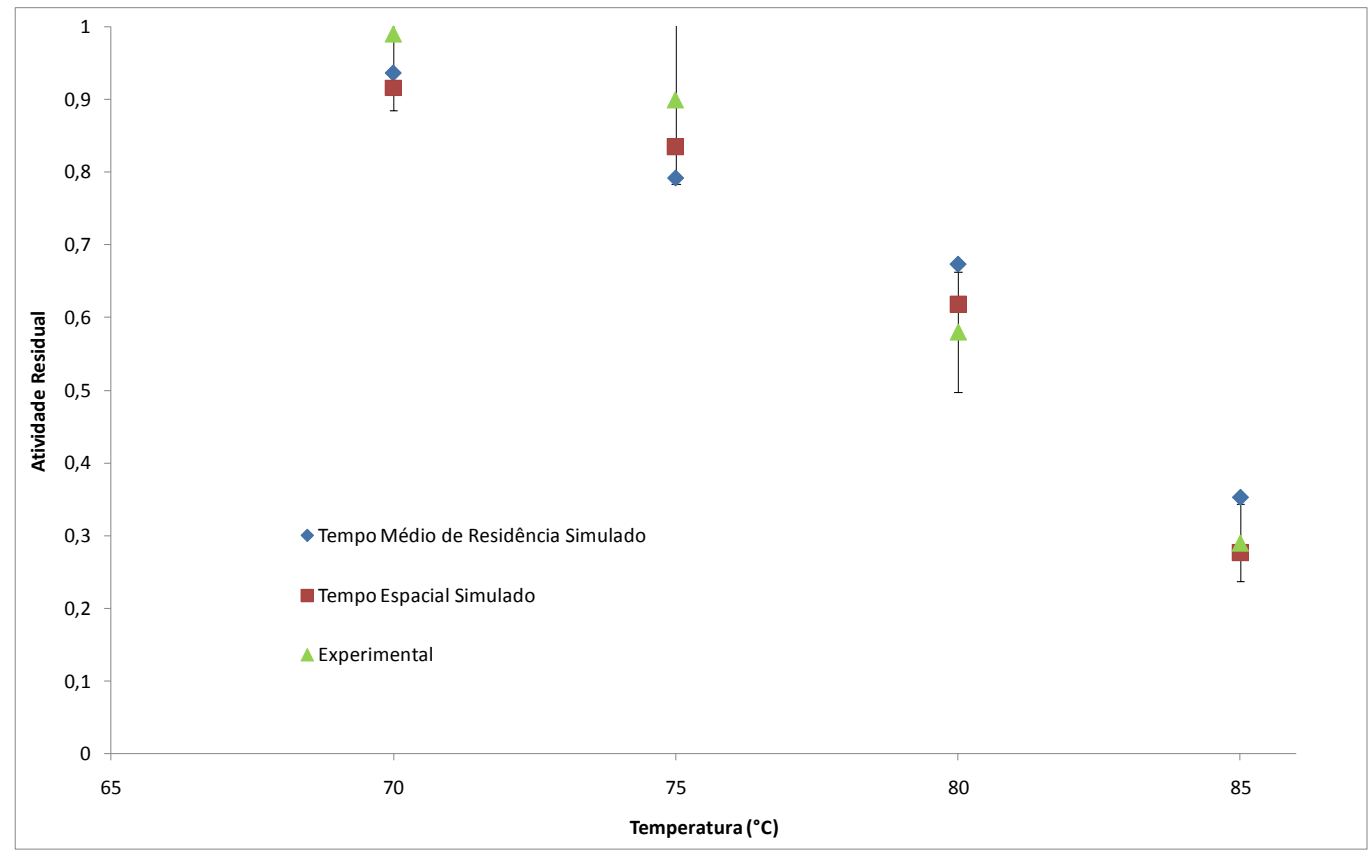

Figura 5-11: Atividade residual experimental e simulada da enzima na saída do aquecimento para processamento a $70,75,80$ e $85^{\circ} \mathrm{C}$. 


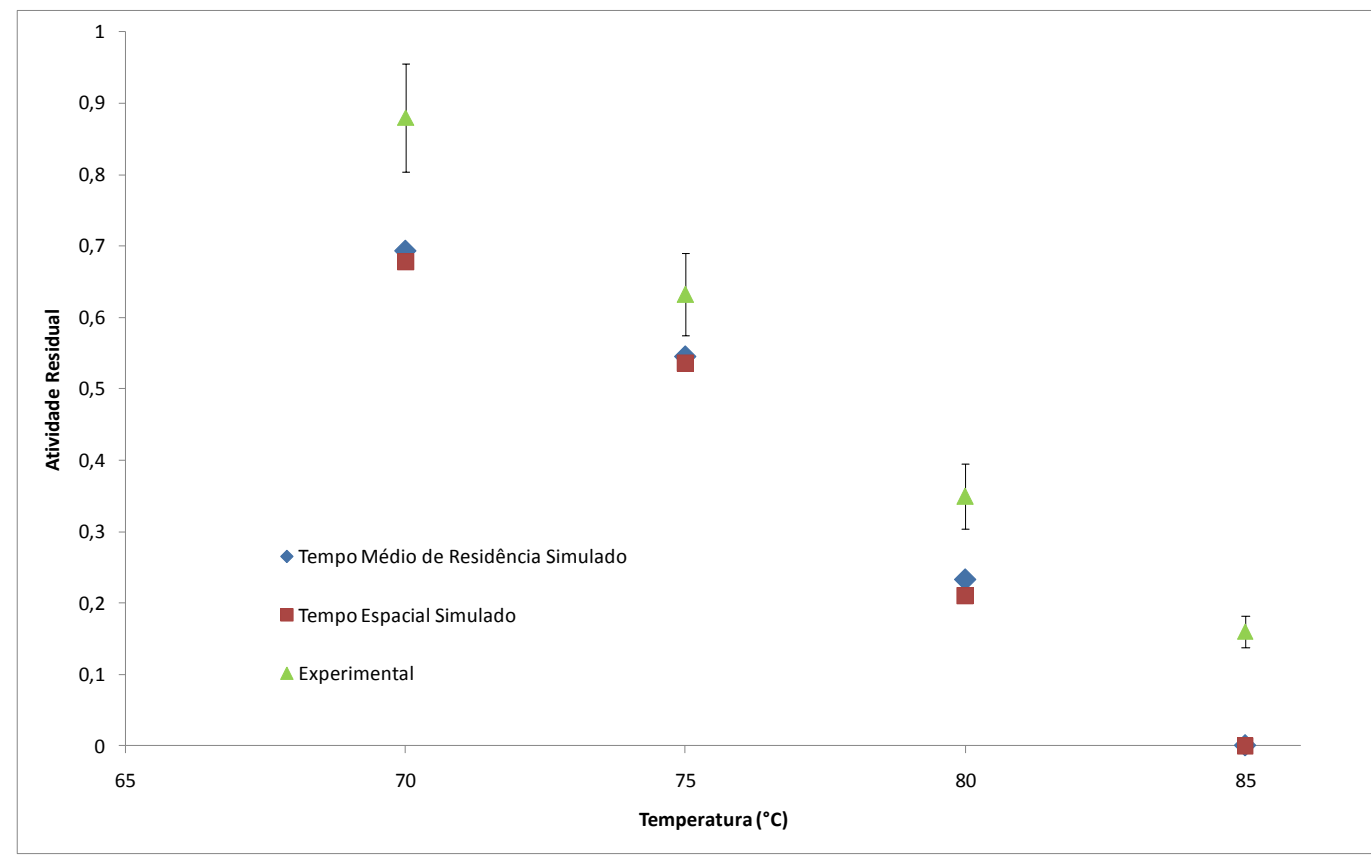

Figura 5-12: Atividade residual experimental e simulada da enzima na saída do resfriamento para processamento a $70,75,80$ e $85^{\circ} \mathrm{C}$.

Para todas as temperaturas de processamento, na saída do aquecimento, os resultados se mostraram coerentes, com o erro experimental englobando os valores de simulação dos modelos com tempo médio de residência e tempo espacial. Foi possível observar que em todas as temperaturas de processamento, na saída do resfriamento, os resultados da simulação usando o modelo com tempo médio de residência ficaram mais próximos dos valores experimentais. Os resultados simulados se mostraram fora do erro experimental e com valores de atividade residual menores dos que os visualizados na realidade. Tal desvio pode ser justificado pelo uso da modelagem do tempo espacial nas conexões tubulares 1 e 2. Com isso, 0 tempo simulado que o fluido percorre nessas regiões é maior do que o experimental, a inativação atingida é maior e o valor da atividade residual fica abaixo da experimental.

A proximidade dos valores simulados com o experimental na saída do resfriamento confirma que o modelo que considera o tempo médio de residência é mais rigoroso, e também por ele considerar que ocorre distribuição de velocidade ao longo do pasteurizador, utilizando o tempo médio, e, assim, esse modelo poderá ser utilizado para continuidade dos estudos. 
Desse modo, as modelagens desenvolvidas e simuladas descrevem bem o comportamento da inativação enzimática no interior do trocador de calor a placas, porém deve ser avaliada a utilização de outra enzima para continuidade da pesquisa ou outro método desde que se obtenha um erro experimental menor.

Essa modelagem poderá encontrar dificuldades, se otimizada em ambiente gPROMS, já que foram encontrados problemas de instabilidade de solução numérica e convergência do modelo para alguns intervalos de valores utilizados nos parâmetros de entrada. A grande variação da ordem de grandeza da concentração $C_{A}$ também traz grande impacto na capacidade de solução do modelo pelo software. 


\section{CONCLUSÕES}

Foi possível desenvolver uma modelagem matemática para determinação do histórico de temperatura e letalidade do processo de pasteurização em trocadores de calor a placas.

Para as simulações referentes ao estudo de caso da Coxiella burnetii, as curvas de temperatura e de distribuição de letalidade se mostraram condizentes com resultados esperados.

O modelo para determinação de atividade residual da enzima fosfatase alcalina em tampão fosfato descreve bem a redução da atividade durante 0 processo de pasteurização no trocador de calor a placas utilizado, o que foi comprovado processando solução enzimática e medindo a atividade residual ao final da seção de aquecimento e da seção de resfriamento. Levando em conta o erro na determinação do valor experimental, os valores referentes à simulação estão contidos no intervalo de desvios na seção de aquecimento.

$\mathrm{Na}$ comparação dos valores de atividade residual experimental e de simulação, pela verificação da saída da seção de resfriamento, foi possível determinar qual dos modelos representou de maneira mais próxima o processo de pasteurização, sendo ele o modelo que contempla o uso do tempo médio de residência nas seções do pasteurizador e tubo de retenção, utilizados na pesquisa.

O modelo desenvolvido tem potencial para ser aplicado em futuros estudos de otimização do processo de pasteurização em trocadores de calor a placas. Essa modelagem também possibilita a avaliação de destruição de outros indicadores alvo, desde que sejam conhecidos seus parâmetros cinéticos. Sugere-se a utilização de outro software que o gPROMS para a otimização, devido às dificuldades encontradas na instabilidade da solução e convergência do modelo.

Algumas sugestões para a continuidade dessa linha de pesquisa são utilizar o modelo desenvolvido em problemas de otimização visando à redução de custos e melhoria dos atributos de qualidade do produto e buscar outro TTI para o estudo experimental da letalidade. 


\section{REFERÊNCIAS BIBLIOGRÁFICAS}

ABIR. Associação brasileira das indústrias de refrigerantes e bebidas nãoalcoólicas. Sucos, 2009. Disponível em $<$ http://www.abir.org.br/article.php3?id article=2768>. Acesso em: 05 de abril 2012.

AGUIAR, H.F. Modelagem matemática e validação experimental da pasteurização de leite pela avaliação do histórico de temperatura e letalidade em trocador a placas. 66 p. Dissertação (Mestrado) - Escola Politécnica, Universidade de São Paulo, São Paulo, 2009.

AGUIAR, H.F.; YAMASHITA, A.S.; GUT, J.A.W. Development of enzymic timetemperature integrators with rapid detection for evaluation of continuous HTST pasteurization processes. Lebensmittel-Wissenschaft + Technologie / Food Science + Technology, 47(1), 110-116, 2012.

ALFA LAVAL Products. The world leader in heat transfer. Plate heat exchanger. Disponível em <http://www.alfalaval.com/solutionfinder/products/gasketed-industrial-range-phe/Documents/M10.pdf>.

Acesso em: 10 de abril 2012.

AWUAH, G.B.; ECONOMIDES, A.; RAMASWAMY, H.S. Thermal Processing and Quality: Principles and Overview. Chemical Engineering and Processing, v. 46, p. 584-602, 2007.

BEJAN, A.; TSATSARONIS, G.; MORAN, M. Thermal design and optimization. New York: John Wiley \& Sons, 1996.

BOBBILI, P.R.; SUNDEN, B.; DAS, S.K. An experimental investigation of the port flow maldistribution in small and large plate package heat exchangers. Applied Thermal Engineering 26 (16), 1919-1926, 2006.

ELEZ-MARTINEZ, P.; MARTIN-BELLOSO, O. Effects of high intensity pulsed electric field processing conditions on vitamin $\mathrm{C}$ and antioxidant capacity of orange juice and gazpacho. Food Chemistry, London, v. 102, p. 201209, 2007.

FELLOWS, P.J., Food Processing Technology: Principles and Practice, 2. ed., CRC Press, New York, 2000.

FERNANDES, C.S.; DIAS, R.; NOBREGA, J.M.; AFONSO, I.M.; MELO, L.F.; MAIA, J.M. Simulation of stirred yoghurt processing in plate heat exchangers. Journal of Food Engineering 69 (3), 281-290, 2005.

FOGLER, H. S. Elements of chemical engineering. 3. Ed.; Prentice Hall, 1120 p., 1999. 
FONSECA, H. Princípios e métodos gerais de conservação de alimentos: conservação pelo calor e pelo frio. CAMARGO, R. (Coord.) Tecnologia dos produtos agropecuários: alimentos. São Paulo: Nobel. Cap. 5, p. 7395, 1984

FOX, P. F.; McSWEENEY, P. L. H. Dairy Chemistry and Biochemistry. 1. Ed. London: Blackie Academic \& professional, p. 324-327, 1998.

FRYER, P.J. The uses of fouling models in the design of food process plant. J. Soc. of Dairy Technol., 42, 23, 1989.

GALEAZZO, F. C. C.; MIURA, R. Y.; GUT, J. A. W.; TADINI, C. C. Experimental and numerical heat transfer in a plate heat exchanger. Chemical Engineering Science, v. 61, n. 21. p. 7133-7138, 2006.

GARETT, B.A.; RIDGES, P.; NOYES, N.J. Fouling of heat exchangers: Characteristics, cost, prevention, control and removal, 1를 Edição, PrenticeHall, Englewood Cliffs, NJ, 1985.

GEORGIADIS, M.C.; MACCHIETTO, S. Dynamic modeling and simulation of plate heat exchangers under milk fouling. Chemical Engineering Science, 1605-1619, 2000

GEORGIADIS, M.C.; ROTSTEIN, G.E.; MACCHIETTO, S. Optimal design and operation of heat exchangers under milk fouling. A.I.Ch.E. Journal, 44, 2099-2111, 1998a.

GEORGIADIS, M.C.; ROTSTEIN, G.E.; MACCHIETTO, S. Modelling and simulation of shell and tube heat exchangers under milk fouling. A.I.Ch.E. Journal, 44, 959-971, 1998b.

GRIJSPEERDT, K.; HAZARIKA, B.; VUCINIC, D. Application of computational fluid dynamics to model the hydrodynamics of plate heat exchangers for milk processing. Journal of Food Engineering, v. 57, p. 237-242, 2003.

GUT, J. A. W. Configurações ótimas para trocadores de calor a placas. 244p. Tese (Doutorado) - Escola Politécnica, Universidade de São Paulo, São Paulo, 2003.

GUT, J. A. W.; PINTO, J. M. Modeling of plate heat exchangers with generalized configurations. International Journal of Heat and Mass Transfer, v. 46, n. 14, p. 2571-2585, 2003a.

GUT, J. A. W.; PINTO, J. M. Conhecendo os trocadores de calor a placas. Revista de Graduação da Engenharia Química. São Paulo, v. 1, n. 11, p. 9-16, 2003b.

GUTIERREZ, C.G.C.C.; DIAS, E.F.T.S.; GUT, J.A.W. Residence time distribution in holding tubes using generalized convection model and numerical convolution for non-ideal tracer detection. Journal of Food Engineering, 98(2), 248-256, 2010. 
GUTIERREZ, C.G.C.C.; DIAS, E.F.T.S.; GUT, J.A.W. Investigation of the residence time distribution in a plate heat exchanger with series and parallel arrangements using a non-ideal tracer detection technique. Applied Thermal Engineering, 31(10), 1725-1733, 2011.

GUTIERREZ, C. G. C. C. Análise dinâmica de um processo de pasteurização HTST. 81p. Exame de Qualificação para o título de Doutor - Escola Politécnica, Universidade de São Paulo, 2012.

HAN, X.H.; CUI, L.Q.; CHEN, S.J.; CHEN, G.M.; WANG, Q. A numerical and experimental study of chevron, corrugated-plate heat exchangers. International Communications in Heat and Mass Transfer 37 (8), 10081014, 2010.

HEWITT, G. F.; SHIRES, G. L.; BOTT, T. R. Process heat transfer. Boca Raton: CRC Press, 1994.

IBARROLA, J. J.; SANDOVAL, J. M.; GARCIA - SANZ, M.; PINZOLAS, M. Predictive control of a high temperature-short time pasteurization process. Control engineering practice, v. 10, n. 7, p. 713-725, 2002.

JUNG, A.; FRYER, P. J. Optimising the quality of safe food: Computational modeling of a continuous sterilization process. Chemical Engineering Science, 54, p. 717-730, 1999.

KECHICHIAN, V.; CRIVELLARI, G.P.; GUT, J.A.W.; TADINI, C.C. Modeling of continuous thermal processing of a non-newtonian liquid food under diffusive laminar flow in a tubular system. International Journal of Heat and Mass Transfer, no prelo, 2012.

LADO, B. H.; YOUSSEF, A. E. Alternative food-preservation technologies: efficacy and mechanisms. Microbes and Infections, v. 4, n. 4, p. 433-440, 2002.

LEVENSPIEL, O. Engenharia das reações químicas. Tradução de Verônica M. A. Calado. 3. Ed. São Paulo: Editora Edgard Blücher, 563 p. 2007.

LEWIS, M.; HEPPELL, N. Continuous thermal processing of foods: pasteurization and UHT sterilization. Gaithersburg, Maryland: Aspen publishers, 447 p., 2000.

LIU, F.B.; TSAI, Y.C. An experimental and numerical investigation of fluid flow in a cross-corrugated channel. Heat and Mass Transfer 46 (5), 585-593, 2010.

MARTH, E. H.; STEELE, J. L. Applied dairy microbiology. 2 ed. New York: Marcel Dekker, 744 p., 2001.

MINISTÉRIO DA AGRICULTURA, PECUÁRIA e ABASTECIMENTO. Brasil: projeções do agronegócio 2010/2011 a 2020/2021, 2011. 
PEARCE, N. plate exchanger defeats industry conservatism. European Power News. p.16-17, Oct. 2001.

RAHMAN, S. Food Properties Handbook. CRC, 1995, 500 p.

RIBEIRO, M. L. Efeito do processamento térmico nas características físicoquímicas, nutricionais, microbiológicas e na atividade enzimática de polpa de mamão formosa (Carica papaya L.), 2009, 103p. Dissertação (Mestrado), Programa de pós-graduação em Ciência e Tecnologia de Alimentos.

SHAH, R. K.; SEKULIC, D. P. Fundamentals of heat exchanger design. New Jersey: John Wiley \& Sons, 941 p., 2003.

TEREDA, F.A.; Srihari, N.; SUNDEN, B.; DAS, S.K. Experimental investigation on port-to-channel flow maldistribution in plate heat exchangers. Heat Transfer Engineering 28 (5), 435-443, 2007.

TOLEDO, R. T. Fundamentals of food process engineering. 2. Ed. New York: Chapman \& Hall, 579 p., 1999.

TRIBESS, T. B. Estudo da cinética de inativação da pectinesterase em suco de laranja natural minimamente processado. 138p. Dissertação (Mestrado) Escola Politécnica, Universidade de São Paulo, São Paulo, 2003.

TRIBESS, T. B. e TADINI, C. C. Suco de laranja naturalmente processado: Uma alternativa para ampliar o mercado de suco de laranja no Brasil. Congresso internacional de economia e gestão de redes agrialimentares, 2003, Ribeirão Preto, Anais.

WALSTRA, P.; GEURTS, T.J.; JELLEMA, A.; NOOMEN, A.; van BOEKEL, M.A.J.S. Dairy Technology: Principles of Milk Properties and Processes. New York: Marcel Dekker, 727 p., 1999.

WANG, L.; SUNDÉN, B.; MANGLIK, R. M. Plate heat exchangers: design, applications and performance. Southampton: WitPress, 269 p., 2007. 